\title{
Processing Trade, Firm Heterogeneity and Export Behavior of Chinese Firms
}

\author{
Min Zhu \\ University of Helsinki and HECER
}

Discussion Paper No. 381

August 2014

ISSN 1795-0562

HECER - Helsinki Center of Economic Research, P.O. Box 17 (Arkadiankatu 7), FI-00014 University of Helsinki, FINLAND, Tel +358-9-191-28780, Fax +358-9-191-28781,

E-mail info-hecer@helsinki.fi, Internet www.hecer.fi 


\title{
Processing Trade, Firm Heterogeneity and Export Behavior of Chinese Firms*
}

\begin{abstract}
In this paper, we have incorporated pure exporters into an asymmetric two-country general equilibrium model by Melitz (2003) to explain trade performance and export patterns in China. This model captures the coexistence of pure exporters, non-exporters and regular exporters in a single unified framework. The paper shows how the presence of domestic trade costs alongside of the sheer magnitude of processing trade drastically affects how the impact of trade is distributed across different types of firms. The least productive firms behave only as pure exporters; the most efficient ones reap benefits from trade in the form of gains in revenue and profit; and less efficient firms focus on the domestic market. On the other hand, the paper shows the existence of domestic and export costs does not affect the welfare-enhancing properties of trade: falling trade costs unequivocally deliver welfare gains in both countries.
\end{abstract}

JEL Classification: F12, F13

Keywords: trade liberalization, heterogeneous firms, domestic trade costs, pure exporters

Min Zhu

Department of Political and Economic Studies

University of Helsinki

P.O. Box 17 (Arkadiankatu 7)

FI-00014 University of Helsinki

FINLAND

e-mail: min.zhu@helsinki.fi

* I am very grateful to Tapio Palokangas and Pertti Haaparanta for thoughtful comments and suggestions. I also would like to thank seminar participants at HECER and University of Helsinki for helpful discussions. Responsibility for the views expressed rest with the author. Comments are very welcome. 


\section{Introduction}

The rising integration of the Chinese manufacturing industry into the world economy has led China's extraordinary trade performance over the past three decades. This spectacular achievement is mainly attributable to the international segmentation and fragmentation of productions in the global scale carried out by foreign multinational enterprises (MNEs). A particular form of this slicing of the valueadded chain is processing trade: the activity of assembling tariff exempted imported inputs into final goods for resale in the foreign markets (Dai et al., 2011). This international processing has been at the core of China's outstanding trade expansion. As a means of export promotion, processing trade has been implemented in China over thirty years and successfully boosted foreign export. It accounts for nearly half of China's exports and for forty percent of its imports in the 2000s. Additionally, the sheer magnitude of processing trade in China has generated a vast number of firms that almost exclusively produce for foreign countries. I refer to these firms as processing exporters 1 . Defever and Riao (2012) report that more than a third of Chinese manufacturing exporters sold nighty percent or more of their output abroad between 2000 and 2006. Gao and Tvede (2013) find that the average share of export-only firms out of all the firms in China is $6.8 \%$, which accounts for $27.56 \%$ of the total export value over the period 1999 and 2008. Processing trade is also gainning popularity in other developing countries. In 2006, processing enterprises from 130 countries employed an estimated 66 million people, accounting for the majority of exports from countries like China, Mexico, the Philippines, Vietnam, and recently sub-Saharan African nations (International Labor Organization, 2007). Motivated by past success, Chinese government still considers processing trade as a fast and efficient path to industrialization and has used various aggressive export policies to encourage it to date.

Despite the importance of processing trade in many developing countries, e.g. China, empirical evidence and theoretical analysis toward processing exporters are scant. Previous studies ${ }^{2}$ have accumulated a rich stock of knowledge about firm-level export patterns in developed countries. They found that exporters tend to be larger and more productive and sell more in the domestic market than their non-exporting counterparts. In particular, participation in international trade is relatively rare and is associated with superior value of productivity and other measures of economic performance $3^{3}$. Nevertheless, the focus has been on the non-processing firms, implying that the framework is not applicable for developing countries that heavily rely on processing trade.

\footnotetext{
${ }^{1}$ pure exporters/processing enterprises/processing exporters are used interchangeably in this paper.

${ }_{2}^{2}$ Bernard and Jensen (1999), Bernard et al. (2003) and Aw et al. (2002) show that across wide range of countries and industrial, employment, shipment, wage, productivity, and capital intensity are all higher than non-exporters at any moment.

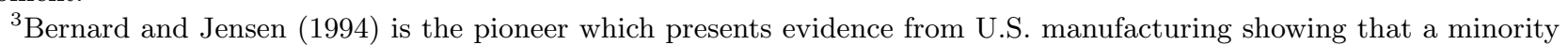
of plants export. Similar findings have emerged for a wide range of other countries, as summarized in Ottaviano et al. (2011) and World Trade Organization (2008).
} 
Processing exporters in China are fundamentally different from the regular exporters, who often passively receive orders and sometimes even intermediate input from foreign buyers. Chinese producers only conduct the final assembly, while the foreign firms are responsible for the entire export activity. Recent empirical research $(\mathrm{Lu}, 2010 ;$ Manova and Yu, 2013; Dai et al., 2011) using the longitudinal plant and firm-level data from China has overwhelmingly substantiated that the processing exporters are the least productive surviving firms. Some of these studies have further shown that processing exporters have the lowest profits, offer the minimum wages, invest the least in $\mathrm{R} \& \mathrm{D}$ and are relatively small in terms of sale. Other studies (Fu, 2011; Fernandes and Tang, 2013; Lemoine, 2010) have highlighted that the processing exporters are concentrated in labor intensive sectors and mainly invested by Foreign Invested Enterprises (FIEs). The presence of pure exporters distinguishes China from developed countries. There are no so-called pure exporters in U.S or France (Bernard and Jensen, 1999; Eaton et al. 2011). The goal of this paper is to incorporate the relevance of pure exporters into the heterogeneous firms literature to further strengthen its explanatory power for developing countries.

By doing so, we propose an extension of Melitz (2003) general equilibrium model into an asymmetric two-country setting. Heterogeneous Chinese firms may choose to operate in either processing trade or regular production regimes, based on their idiosyncratic productivity. However, firms in foreign country(e.g. the U.S) can only pursue regular production mode. This asymmetric assumption matches the fact that processing trade is only implemented in developing countries. We also introduce fixed domestic trade costs, which could induce firms to export but not serve the domestic market, especially for firms which have cheap export costs. These two assumptions capture the salient features of processing trade in China. To operate in processing trade, firms in China need to fully withdraw from the domestic market and sell all of their output in foreign market in order to benefit from policies such as a host of tax concessions. In other words, there is no domestic trade costs associated with pure exporters as products manufactured by them are not allowed to be sold in the Chinese market. Additionally, as processing exporters passively receive orders from foreign buyers, without the need to investigate the foreign markets and outreach to potential foreign buyers, the fixed export costs are also neglected.

The aforementioned model is able to reproduce many characteristics of export patterns of Chinese firms emphasized by recent micro-level studies 4 . We show that the presence of domestic trade costs along with the enforcement of processing trade generate processing exporters in China. Firms with both domestic and foreign market have the highest production efficiency, followed by firms with domestic sales, and finally by pure exporters. This model also allows us to explore how the impact of trade liberalization is distributed across different types of firms. Specifically, reductions in export trade

\footnotetext{
${ }^{4}$ Zhang et al. (2009) using firm-level manufacturing data from Jiangsu province document that productivity indeed serves as a key determinant of export success, but export did not improve firms' performance. By using nearly 3 million industrial firms over the period 1998-2007. Li and Yin (2009) ascertain that non-exporters are more productive than exporters and there is a negative correlation between being an exporter and firm's productivity. Lu et al. (2010) have found evidence that foreign affiliates exporters in China are less productive than non-exporters.
} 
barriers induce better-performing regular firms benefit from globalization through expanding market; while worse-performing regular firms suffer from globalization through contracting market. The least productive pure exporters in China are forced to exit the market, and there is a revenue loss for surviving firms that only serve the foreign market. Each of these responses reallocates resources toward more productive firms and generates improvement in aggregate productivity levels.

Trade liberalization in variable trade costs delivers very similar effects to falling export barriers. High-productive regular exporting firms experience increased revenue through greater foreign sales. The most efficient domestic regular firms are able to overcome the cost of entering exporting market, thereby inducing the entry of new regular exporters in both countries. In contrast, the rapidly falling transport cost forces the least productive Chinese regular firms to switch from the regular production mode to processing trade, and attract even less productive Chinese firms into processing trade regime, which leads to the expansion of pure exporters. In other words, low efficient manufacturers might benefit from falling transportation costs. Implementing processing trade in China potentially allows producers that would have otherwise been forced to exit firms to pursue cross-border operations and gain from trade. Furthermore, trade generates aggregate productivity gains for firms in the foreign country as low-productive firms exit and high-productive firms expand. The overall industrial productivity of Chinese firms after trade liberalization is ambiguous.

Our analysis related to fixed domestic trade barriers imply that productivity constrained firms, and presumably the segmented domestic market as a whole, might be stuck in low value-added stages of supply chain and unable to pursue more profitable opportunities. Integrating the Chinese domestic market might be thus an important prerequisite for moving into higher value-added, more profitable activities. Our results indicate that these effects can be sizable. Reducing the domestic trade protectionism would increase aggregate welfare and expand the total varieties for consumption. This conclusion also sheds light on the gains from falling domestic trade costs in the context of heterogeneous firms. First, reducing impediment to interprovincial trade could facilitate access to the domestic market. The most productive pure exporters would find it profitable to enter the domestic market as domestic trade costs fall, thereby more domestic Chinese firms enter the local market. This, in turn, implies the expansion in the range of product varieties available to Chinese consumers. Second, as low efficient pure exporters exit and high efficient ones pursue regular production mode, the mass of firms engaging in processing trade declines. This is particularly beneficial for China, which could substantially reduce the heavy reliance on processing trade for growth. As is pointed out in Wong (2012), since domestic trade is almost as twice as large as international trade in the Chinese economy, it could overtake international trade as the more important driver of China's growth if the decline in domestic barriers were to accelerate. Furthermore, a unified national market could boost the domestic demand and keep the Chinese economy expanding while overseas markets remain weak. 
Our model can also be used to evaluate the welfare consequences of increased exposure to trade in the presence of pure exporters. Trade liberalization and domestic integration unequivocally lead to welfare gains. However, the welfare improvement generated by a reduction in variable trade costs is counteracted by the distortion stemmed from the expanded number of pure exporters operating in China. The accession to WTO in 2001 triggered a sharp rise in the processing trade, which have become the major component of China's export and the essential vehicle of China's trade surge in 2000s. To this end, our model is well-suited to explain the observed empirical pattern that falling transport costs are related to the increasing number of pure exporters in China.

More broadly, our analysis contributes to the following strand of literature. It speaks to the emerging research on export-platform foreign direct investment (FDI) i.e. on MNEs that process their final goods in developing countries (Helpman et al. 2004; Yeaple, 2009). The contribution is that we include a better understanding of how and why firms operate at different stages along the value added chain. There has also been increased interest in the cost and benefits resulting from China's processing trade regime (Fu, 2011; Ma et al. 2009) as well as to the large body of research investigating the welfare implication of export processing zones and duty drawbacks (Fernandes and Tang, 2013; Manova, 2013). Through our novel mechanism of choice of trade regime, less efficient firms in labor-abundant countries are very likely stuck in processing trade. To this line of research, we illustrate productivities constraint impede firms' export outcomes and profits. Our analysis of pure exporters is also related to the literature studying trade policy in a heterogeneous-firm setting (Defever and Riao, 2012, Lu et al., 2014; Fan et al., 2013; Ma et al., 2014). From this point, our theoretical model demonstrates that the reallocation process is hindered, and that trade liberalization does not generate aggregate productivity gains in industries when processing trade is pervasive.

This paper is organized as follows. Section 2 presents the institutional background on processing trade regime in China. After developing the model with heterogeneous firms in Section 3, we carry out an analysis of the impact of trade liberalization on productivity cutoffs and welfare in Section 4. Section 5 concludes.

\section{Institutional Background}

In the hopes of obtaining foreign technology, utilizing abundant labor force and boosting economic growth, China has employed a wide range of trade instruments to stimulate export activity and FDI since the beginning of the 1980s. A key intervention is the attraction of FIEs carrying out processing trade. In place since the 1980s, the provision of this policy has resulted in a far-reaching reshuffle of industrial production at the world level. China has become a world factory and climbed to the top of the world exporters, contributing for more than ten percent of the global trade volume (the sum 
of exports and imports) in 2010. Most importantly, processing trade constitutes almost one-half of China's total trade and becomes the major contributor to China's trade surplus.

The prevalence of processing trade can be directly attributed to the following factors: the establishment of Free Trade Zones (FTZs) $5^{5}$ and the attraction of FDI. In the 1980s, the Chinese authority selected some coastal cities as Special Economic Zones (SEZs) to stimulate trade. FIEs were strongly encouraged to locate in these zones to engage in processing trade. Additionally, the export-oriented firm (with the export volume more than fifty percent) invested by foreign investors likewise granted additional benefits such as reduced corporate income tax rate, preferential land-use policies, easier access to finance and foreign market. In particular, enterprises located in SEZs were free to use the Chinese vast pool of low cost labor, which was different from the prevailing Chinese lifetime system of public or collective firms. These polices have proven to be highly effective, resulting in the increase of China's share in world trade from 1.1 percent to 1.9 percent by the end of 1989.

Since the 1990s, the labor-intensive stage of industrial production has been relocated from high-wage countries to low-wage countries, which have specialized in assembly. In order to actively participate in this new form of division of labor and integrate into the global production network, China deepened its trade reform and broadened the opening-up in early of 1992. Policies with the similar privileges were extended to inland and western provinces. Various economic development zones and high-tech development zones were also established in central and western China. In addition, China progressively lowered foreign investors' import duties and entry barriers. These measures have led to impressive FDI flows to China and given rise to the massive investment in manufacturing industry. FIEs accelerate the Chinese manufacturing industry into the global production chain as they fragmented large parts of their production processes via arms-length contracts or subsidiaries in China. Notably, FIEs overwhelmingly accounted for seventy percent of processing trade in China in the first decade of the twenty-first century. This highlights the essential role of foreign firms in China's ballooning trade surplus.

The most direct and profound policy in promoting processing trade and enhancing export is the establishment of a series of Export Processing Zones (EPZs) in the year 2000, one year before China joined the WTO. Chinese private firms, State-Owned Enterprises (SOEs) and FIEs are all encouraged to locate in the EPZs, but all firms are only allowed to engage in processing trade. The production inputs entering the EPZs are duty free and the final assembled product for export are exempted from value added tax. Furthermore, firms also enjoy other preferential policies as streamlined regulations, minimal administrative costs and finance facilities. In other words, the EPZs in China are very simple zones that have the highest levels of openness in the country (Fu and Gao, 2007). However, in order

\footnotetext{
${ }^{5}$ The FTZs in China include: Special Economic Zones (SEZs), Economics and Technological Development Zones (ETDZs), High-Technology Industrial Development Zones (HTIDZs), Export Processing Zones (EPZs), Open coastal/riverside/inland/borader city, Border Economic Cooperation Zone (BECZ), Bounded Zone/Logistics Park.
} 
to obtain these benefits, all firms located in the EPZs must export seventy percent of their output. The set up of the EPZs substantially encourages MNEs to transfer their labor intensive stage to China. The aggressive expansion of EPZs in China has led to a great leap forward in China's foreign trade, accounting for almost nine percent of world export in 2008.

In summary, the creation of processing trade regime has significantly contributed to the growth of China's export activity. Foreign firms are the key determinants to the expansion of processing trade. The establishment of a large number of FTZs further consolidates its superior export performance.

\section{Theoretical Framework}

The model extends Melitz (2003) to a world of two large asymmetric countries, China and Foreign Country indexed by $i \in\{c, f\}$ accordingly. Each country is populated by $L_{i}$ identical household. Labor is the only factor of production. Each household inelastically supplies one unit of labor and earns wage $w_{i}$. We assume that China is a labor-abundant country, having a lower wage than that of the Foreign Country $\left(w_{c}<w_{f}\right)$. The size of the two economies is equal $\left(L_{c}=L_{f}=L\right)$.

\subsection{Demand}

The preferences of a representative consumer in country $i$ are given by a $C E S$ utility function over a continuum of goods indexed by $\omega$ :

$$
U_{i}=\left[\int_{\omega \in \Omega_{i}} q_{i}(\omega)^{\rho} d \omega\right]^{\frac{1}{\rho}}, i \in\{c, f\}
$$

where the measure of the set $\Omega_{i}$ represents the mass of available varieties in country $i$. These goods are substitutes, which implies $0<\rho<1$ with the elasticity of substitution between any two pair of goods having $\sigma=\frac{1}{1-\rho}>1$. Following Dixit and Stiglitz (1975), consumer behavior can be modeled by considering the set of varieties consumed as an aggregate good $Q_{i} \equiv U_{i}$ associated with an aggregate price in country $i$

$$
P_{i}=\left[\int_{\omega \in \Omega_{i}} p_{i}(\omega)^{1-\sigma} d \omega\right]^{\frac{1}{1-\sigma}} .
$$

The assumption of CES preference implies that the consumer has "taste for variety" in that she/he prefers to consume a diversified bundle of goods. Moreover, even if each variety is priced differently, adding a new one increases utility if prices of the existing varieties are unchanged. Given these presences, the revenue of a variety $\omega$ in country $i$ is:

$$
r_{i}(\omega)=R_{i}\left[\frac{p_{i}(\omega)}{P_{i}}\right]^{1-\sigma}
$$

where $R_{i}=P_{i} Q_{i}=\int_{\omega \in \Omega_{i}} r_{i}(\omega) d \omega$ is the aggregate expenditure in country $i$; $p_{i}(\omega)$ denotes the price of variety $\omega$ in the domestic market $i$; the price index $P_{i}$ summarizes the prices of competing varieties. 


\subsection{Production}

There is a continuum of firms, each choosing to produce a different variety $\omega$ with productivity $\varphi$. Production involves fixed overhead costs and variable costs in each period. Production requires only one factor, labor, which is inelastically supplied at its aggregate level $L_{i}$, an index of the country $i$ 's size. A firm in country $i$ pays the fixed market access costs $f_{x} w_{i}$ to serve consumers in country $j$. We denote the fixed costs of serving domestic market by $f_{d} w_{i}$, which includes "market access" costs into the domestic market 6 . Exporting involves symmetric iceberg trade costs, where $\tau \geq 1$ units of a good must be shipped in order for one unit to arrive. All firms in both countries face the fixed overhead costs $f w_{i}$, and vary in firm productivity, $\varphi \in(0, \infty)$.

In particular, a Chinese firm chooses to either pursue processing trade or regular production mode. A pure exporter engages in processing trade which exports all of their product by paying beachhead costs $f w_{c}$. On the other hand, a regular producer that has the capability to cover beachhead costs $f w_{c}$ and domestic trade costs $f_{d} w_{c}$ serves the Chinese domestic market. Some of these regular producers that are able to pay the additional fixed export costs $f_{x} w_{c}$ exporting to Foreign Country. Notably, we assume that firms in Foreign Country only operate domestically or as regular exporters.

Pure exporters are engaged in processing trade, and it is only implemented in China. Under this regime, the duty of the imported input is waived and the processed goods are not allowed to be sold in the Chinese market. Pure exporters in China thus pay for all domestic and manufactured input and labor, and foreign buyers are responsible for the marketing and distribution of the final goods. In other words, pure exporters only need to bear the production costs $f w_{c}$ and the iceberg trade costs $\tau>1$ of transportation. The fixed domestic trade costs $f_{d} w_{c}$ and the fixed export costs $f_{x} w_{c}$ are waived from their cost structure owing to the definition of processing trade. This is the key assumption which fits the empirical findings that processing trade is prevalent in developing country e.g. China. By contrast, the up-front expenditures are highest for a ordinary exporter that bears all domestic trade costs $f_{d} w_{c}$, export distribution outlays associated with production $f w_{c}$ and trade $f_{d} w_{c}$. A firm that only serves the domestic market has lower up-front expenses as it entails beachhead cost $f w_{c}$ and domestic trade barriers $f_{d} w_{c}$.

Firm technology is represented by a cost function which exhibits constant marginal cost with some fixed costs. The labor used is thus a linear function of output $q$ :

$$
l=\left(F+\frac{q}{\varphi}\right) w_{i}
$$

where $F \in\left\{f, f+f_{d}, f+f_{d}+f_{x}\right\}$. The profit maximization yields the standard condition that a firm's

\footnotetext{
${ }^{6}$ As stated by (Melitz and Redding, 2012), with positive domestic access costs, it can be profitable in principle for firms to export but not to serve the domestic market .
} 
output price is a constant markup over its marginal cost:

$$
\begin{aligned}
& p_{c}^{s}(\varphi)=\frac{\sigma}{\sigma-1} \frac{\tau}{\varphi} w_{c}, \\
& p_{c}^{d}(\varphi)=\frac{\sigma}{\sigma-1} \frac{1}{\varphi} w_{c}, \\
& p_{c}^{x}(\varphi)=\frac{\sigma}{\sigma-1} \frac{\tau}{\varphi} w_{c},
\end{aligned}
$$

where $p_{c}^{s}(\varphi)$ is the price charged by a Chinese pure exporter in Foreign Country; $p_{c}^{d}(\varphi)$ is the price charged by a domestic Chinese firm in its own market, and $p_{c}^{x}(\varphi)$ is the price charged by a regular Chinese exporter in Foreign Country. All exporting firms face the traditional iceberg transportation costs where $\tau>1$ units of a good must be shipped in order for one unit to arrive at its destination.

Substituting the pricing rule into firm revenue (3), we obtain the following expression of a Chinese firm revenue in a different market:

$$
\begin{aligned}
& r_{c}^{s}(\varphi)=\left(\tau w_{c}\right)^{1-\sigma} R_{f}\left(P_{f} \rho \varphi\right)^{\sigma-1}, \\
& r_{c}^{d}(\varphi)=w_{c}^{1-\sigma} R_{c}\left(P_{c} \rho \varphi\right)^{\sigma-1}, \\
& r_{c}^{x}(\varphi)=\left(w_{c} \tau\right)^{1-\sigma} R_{f}\left(P_{f} \varphi \rho\right)^{\sigma-1},
\end{aligned}
$$

where $r_{c}^{s}(\varphi)$ stands for the total revenue of a Chinese pure exporter gained in Foreign Country; the equilibrium revenue of a Chinese regular producer in the domestic market is $r_{c}^{d}(\varphi)$, and in the export market is $r_{c}^{x}(\varphi)$.

Let $k \in\{d, x, s\}$ index the three possible modes of production: domestic, regular and pure export respectively. The maximum level of profits that a Chinese firm with productivity $\varphi$ using operation mode $k$ can attain is given by:

$$
\pi_{c}^{k}(\varphi)= \begin{cases}\frac{r_{c}^{d}(\varphi)}{\sigma}-\left(f_{d}+f\right) w_{c} & \text { only serves the domestic market } \\ \frac{r_{c}^{d}(\varphi)}{\sigma}+\frac{r_{c}^{x}(\varphi)}{\sigma}-\left(f_{d}+f_{x}+f\right) w_{c} & \text { serves both markets } \\ \frac{r_{c}^{s}(\varphi)}{\varphi}-f w_{c} & \text { only serves the Foreign Country }\end{cases}
$$

The departure of my model from Melitz (2003) is the additional assumption in the domestic trade costs $f_{d}$. In Melitz (2003), an integrated domestic market which involves no trade costs is assumed. Owing to the cost saving advantage, less-productive firms earn nonnegative profits exclusively from the domestic market. Such an assumption is reasonable since conducting international business is much harder than building business relations in its home market in a unified market. However, Chinese domestic market is segmented by provincial border; the productivity premium is also needed to enter other domestic provincial markets. The best example is by Naughton $(2000)$, which states that local government not block the border or impose any tariffs. But the government's pervasive political power enables it to impose significant non-tariff barriers ${ }^{7}$ to outside firms which can substantially increase

\footnotetext{
${ }^{7}$ The types of domestic trade barriers include physical barriers, outright prohibition through administrative decree, financial benefits for firms selling local goods, local purchasing quotas, poor infrastructure and business conditions, less efficient government (Wong, 2012, Pflüger and Russek, 2013).
} 
the costs of trade and cross-provincial border investments. Regardless of the form of the barriers, these non-tariff barriers are widely employed as trade impediments in domestic trade 8 Therefore, generalized the current theoretical model to capture the salient feature of high domestic trade costs $f_{d}$ is very reasonable.

Foreign firms are similar to Chinese firms. The price charged by a foreign firm in its domestic market is $p_{f}^{d}=\frac{\sigma}{\sigma-1} \frac{1}{\varphi} w_{f}$. The price of a product from Foreign Country exported to the Chinese market is $p_{f}^{x}=\frac{\sigma}{\sigma-1} \frac{\tau}{\varphi} w_{f}$. Thus, the revenue earned from domestic sales and export sales to the Chinese market are, respectively, $r_{f}^{d}(\varphi)=w_{f}^{1-\sigma} R_{f}\left(P_{f} \rho \varphi\right)^{\sigma-1}$ and $r_{f}^{x}(\varphi)=\left(w_{f} \tau\right)^{1-\sigma} R_{c}\left(P_{c} \varphi \rho\right)^{\sigma-1}$, where $R_{i}$ and $P_{i}$ denote the aggregate expenditure and price index in country $i \in\{c, f\}$. The combined revenue of a foreign firm, $r_{f}(\varphi)$, thus depends on its export status:

$$
r_{f}(\varphi)= \begin{cases}r_{f}^{d}(\varphi) & \text { if the firm does not export } \\ r_{f}^{d}(\varphi)+r_{f}^{x}(\varphi) & \text { if the firm exports. }\end{cases}
$$

As illustrated before, foreign firms can only operate domestically or as regular exporters, therefore, no foreign firms ever export and not also produce for its domestic market. Each firm's profit is separated into portions earned from domestic sales $\pi_{f}^{d}(\varphi)$ and export sales $\pi_{f}^{x}(\varphi)$ by accounting the entirely overhead production costs in domestic profit:

$$
\pi_{f}^{d}(\varphi)=\frac{r_{f}^{d}(\varphi)}{\sigma}-\left(f_{d}+f\right) w_{f} ; \quad \pi_{f}^{x}(\varphi)=\frac{r_{f}^{x}(\varphi)}{\sigma}-f_{x} w_{f}
$$

A foreign firm that produces for its domestic market and exports if $\pi_{f}^{x}(\varphi) \geq 0$. Each firm's combined profits can then be written as $\pi_{f}(\varphi)=\pi_{f}^{d}(\varphi)+\max \left\{0, \pi_{f}^{x}(\varphi)\right\}$.

\subsection{Firm Entry, Exit and Export Status}

To produce in country $i \in\{c, f\}$, firms must make an initial investment $f_{e} w_{i}>0$ (measure in units of labor), which is thereafter sunk. Firms then draw their productivity $\varphi$ from a distribution $g(\varphi)$, with cumulative distribution $G(\varphi)$, which is assumed to be common across countries. Firms then face an exogenous probability of death each period $\delta$. An entering firm with productivity $\varphi$ would then immediately exit if its profit level is negative, or would produce and earn $\pi_{i} \geq 0, i \in\{c, f\}$ in every period until it is hit with the bad shock and is forced to exit. Assuming that there is no time discounting, each firm's value function is given by:

$$
v_{i}(\varphi)=\max \left\{0, \sum_{t=0}^{\infty}(1-\delta)^{t} \pi_{i}(\varphi)\right\}=\max \left\{0, \frac{1}{\delta} \pi_{i}(\varphi)\right\} .
$$

\footnotetext{
${ }^{8}$ Domestic trade barriers are not specific to China. For example, in Russia, regional government limits beer import from other regions (Wong, 2012 Guriev et al. 2007).
} 
Thus, $\varphi_{i}^{*}=\inf \left\{\varphi: v_{i}(\varphi)>0\right\}$ identifies the lowest productivity level (hereafter referred to as the cutoff level) of producing firms. Since $\pi_{i}(0)=-f$ is negative, $\pi_{i}\left(\varphi^{*}\right)$ must be equal to zero. This will be referred to as the zero cutoff profit condition.

In particularly, a Chinese firm obtains the information about its productivity level $\varphi$ once the fixed entry costs $f_{e} w_{c}$ are paid. The cutoff productivity levels $\varphi_{s}^{*}, \varphi_{d}^{*}$ and $\varphi_{x}^{*}$ that identify pure exporters, domestic firms and regular exporters:

$$
\begin{aligned}
\varphi_{s}^{* \sigma-1} & =\frac{\sigma f w_{c}}{R_{f}\left(\frac{\tau w_{c}}{P_{f}} \frac{\sigma}{\sigma-1}\right)^{1-\sigma}}, \\
\varphi_{d}^{* \sigma-1} & =\frac{\sigma\left(f+f_{d}\right) w_{c}}{R_{c}\left(\frac{w_{c}}{P_{c}} \frac{\sigma}{\sigma-1}\right)^{1-\sigma}}, \\
\varphi_{x}^{* \sigma-1} & =\frac{\sigma f_{x} w_{c}}{R_{f}\left(\frac{\tau w_{c}}{P_{f}} \frac{\sigma}{\sigma-1}\right)^{1-\sigma}} .
\end{aligned}
$$

These three cutoffs are, respectively, the productivity level above which a Chinese firm would find it profitable to produce solely for Foreign Country $\left\{\pi_{c}^{s}(\varphi)=0\right\}$, and the productivity level necessary for a firm to choose to become a domestic producer $\left\{\pi_{c}^{d}(\varphi)=0\right\}$. Additionally, $\varphi_{x}^{*}=\inf \left\{\varphi: \varphi \geq \varphi_{d}^{*}\right.$ and $\left.\pi_{c}^{x}(\varphi)>0\right\}$ represents the cutoff productivity level for regular exporting Chinese firms.

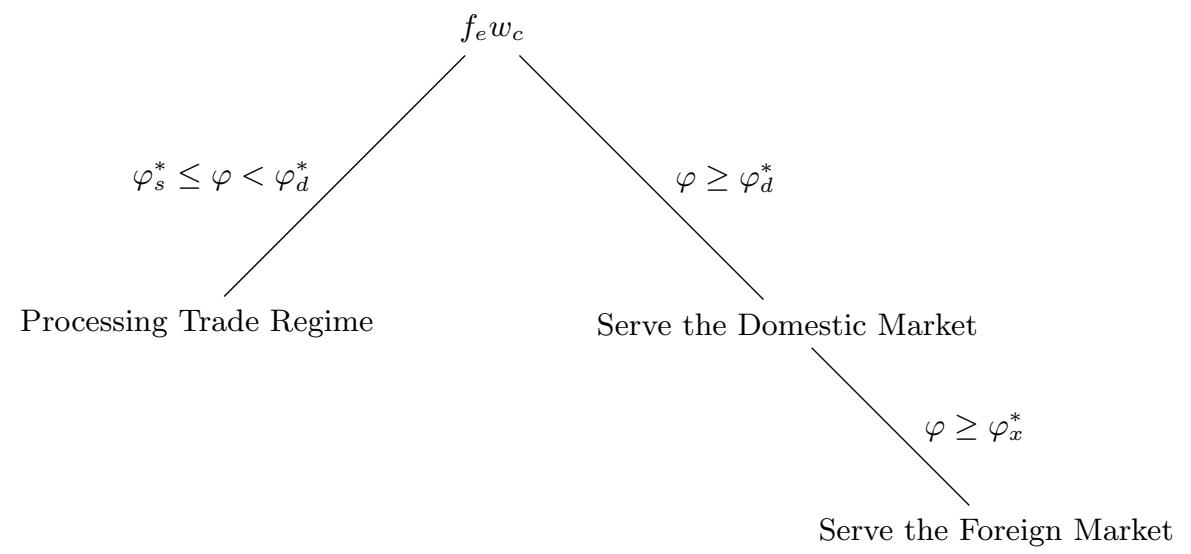

Figure 1: Firms' production mode in China

As shown in Figure 1, successful entrants choose to engage in processing trade or regular production mode based on their idiosyncratic productivity. In accordance with the empirical evidence that Chinese pure exporters are the least efficient surviving firms and exporters tend to be more productive than domestic firms, we must have

$$
\tau^{\sigma-1} f R_{c} P_{c}^{\sigma-1}<\left(f+f_{d}\right) R_{f} P_{f}^{\sigma-1}<\tau^{\sigma-1} f_{x} R_{c} P_{c}^{\sigma-1}
$$

which recaps the partitioning of firms $0<\varphi_{s}^{*}<\varphi_{d}^{*}<\varphi_{x}^{*}$. That is, a Chinese firm, the productivity of which covering the fixed production cost serves Foreign Country only. A Chinese firm, the productivity 
of which is able to pay for the production and fixed domestic trade costs, chooses to serve the domestic market. A Chinese firm drawing a sufficiently high productivity chooses to serve both markets.

Any entering Chinese firm drawing a productivity level $\varphi<\varphi_{s}^{*}$ immediately exit and never produce. The equilibrium productivity distribution $\mu_{c}(\varphi)$ of Chinese firms is determined by the initial productivity draw, conditional on successful entry:

$$
\mu_{c}(\varphi)= \begin{cases}\frac{g(\varphi)}{1-G\left(\varphi_{s}^{*}\right)} & \text { if } \varphi \geq \varphi_{s}^{*} \\ 0 & \text { otherwise }\end{cases}
$$

and $p_{c}^{i n} \equiv 1-G\left(\varphi_{s}^{*}\right)$ is the Chinese firms' ex ante probability of successful entry to the industry. Therefore, the average productivity levels of pure exporters $\tilde{\varphi}_{c}^{s}\left(\varphi_{s}^{*}\right)$, non-exporters $\tilde{\varphi}_{c}^{d}\left(\varphi_{d}^{*}\right)$, and regular exporters $\tilde{\varphi}_{c}^{x}\left(\varphi_{x}^{*}\right)$ in China are defined as:

$$
\begin{aligned}
& \tilde{\varphi}_{c}^{s}\left(\varphi_{s}^{*}\right)=\left[\frac{1}{G\left(\varphi_{d}^{*}\right)-G\left(\varphi_{s}^{*}\right)} \int_{\varphi_{s}^{*}}^{\varphi_{d}^{*}} \varphi^{\sigma-1} g(\varphi) d \varphi\right]^{\frac{1}{\sigma-1}}, \\
& \tilde{\varphi}_{c}^{d}\left(\varphi_{d}^{*}\right)=\left[\frac{1}{1-G\left(\varphi_{d}^{*}\right)} \int_{\varphi_{d}^{*}}^{\infty} \varphi^{\sigma-1} g(\varphi) d \varphi\right]^{\frac{1}{\sigma-1}}, \\
& \tilde{\varphi}_{c}^{x}\left(\varphi_{x}^{*}\right)=\left[\frac{1}{1-G\left(\varphi_{x}^{*}\right)} \int_{\varphi_{x}^{*}}^{\infty} \varphi^{\sigma-1} g(\varphi) d \varphi\right]^{\frac{1}{\sigma-1}} .
\end{aligned}
$$

These equations show how the shape of equilibrium distribution of productivity levels is tied to the exogenous ex ante distribution $g(\varphi)$ while allowing the range of productivity levels (indexed by the cutoffs) to be endogenously determined (Melitz, 2003).

Chinese firms' decisions concerning production for the domestic and foreign markets are summarized graphically in Figure 2 . In addition, $p_{c}^{s}=\frac{G\left(\varphi_{d}^{*}\right)-G\left(\varphi_{s}^{*}\right)}{1-G\left(\varphi_{s}^{*}\right)}$ denotes the probability of being pure exporters conditional on successful entry. Similarly, $p_{c}^{d}=\frac{1-G\left(\varphi_{d}^{*}\right)}{1-G\left(\varphi_{s}^{*}\right)}$ represents the ex ante probability that one of these successful firms engages in regular production mode; while $p_{c}^{x}=\frac{1-G\left(\varphi_{x}^{*}\right)}{1-G\left(\varphi_{d}^{*}\right)}$ denotes the probability of exporting conditional on serving the domestic market. Furthermore, $M_{c}$ is the mass of producing firms and $M_{c}^{e}$ is the mass of entrants in China. Consequently, the mass of pure exporters, domestic firms and exporting firms in China are represented by $M_{c}^{s}=p_{c}^{s} M_{c}, M_{c}^{d}=p_{c}^{d} M_{c}$, and $M_{c}^{x}=p_{c}^{x} M_{c}^{d}$, respectively.

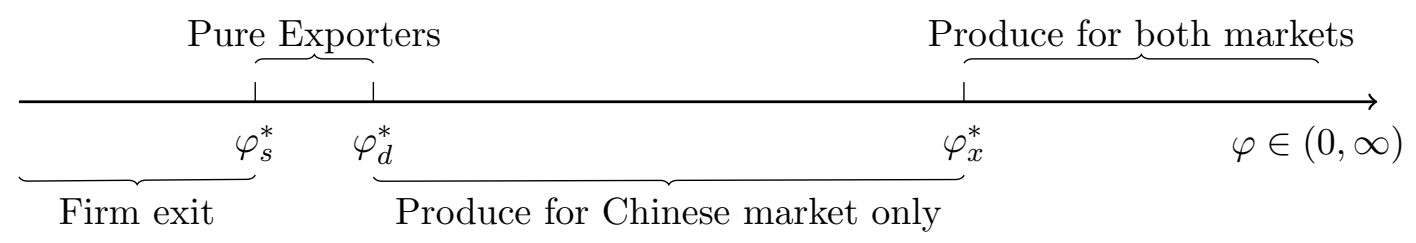

Figure 2: Zero-profit, pure exporting and regular exporting productivity in China

Foreign firms follow the conventional pattern in literature. Once the sunk costs of entry $f_{e} w_{f}$ are paid, a firm draw its productivity $\varphi$ from a fixed distribution $g(\varphi)$. There are two cutoff productivities, 
the domestic zero profit productivity, $\varphi_{d f}^{*}$, above which firms produce for their own domestic market; and the exporting productivity cutoff, $\varphi_{x f}^{*}$, above which firms serve both markets:

$$
\begin{aligned}
\varphi_{d f}^{* \sigma-1} & =\frac{\sigma\left(f+f_{d}\right) w_{f}}{R_{f}\left(\frac{w_{f}}{P_{f}} \frac{\sigma}{\sigma-1}\right)^{1-\sigma}}, \\
\varphi_{x f}^{* \sigma-1} & =\frac{\sigma f_{x} w_{f}}{R_{c}\left(\frac{\tau w_{f}}{P_{c}} \frac{\sigma}{\sigma-1}\right)^{1-\sigma}} .
\end{aligned}
$$

The conventional sorting condition of selection into export market $\left(\varphi_{x f}^{*}>\varphi_{d f}^{*}\right)$ requires strictly positive fixed exporting costs and sufficient high values of both fixed and variable trade costs: $\tau^{\sigma-1} f_{x} R_{f} P_{f}^{\sigma-1}>$ $\left(f+f_{d}\right) R_{c} P_{c}^{\sigma-1}$. In this sense, the revenue needed to serve the export market is larger relative to the revenue needed to cover the domestic trade costs.

$\overbrace{\underbrace{\varphi_{d f}^{*}}_{\text {Produce for Foreign Country only }} \varphi_{x f}^{*}}^{\text {Pirm exit }} \overbrace{}^{\text {Produce for both markets }}$

Figure 3: Zero-profit and exporting productivity in Foreign Country.

Foreign firms' decision concerning production for their own domestic market and Chinese market are summarized graphically in Figure 3. Of the mass of foreign firms, $M_{f}, G\left(\varphi_{d f}^{*}\right)$, draw a productivity level sufficient low that they are unable to cover any costs and exit the industry immediately; a fraction, $G\left(\varphi_{x f}^{*}\right)-G\left(\varphi_{d f}^{*}\right)$, draw an intermediate productivity such that they could afford the costs of production and domestic trade barriers and serve its own domestic market; a fraction, $1-G\left(\varphi_{x f}^{*}\right)$, has a sufficient high productivity level that it is profitable to serve both markets. Once again, the equilibrium distribution of productivity for incumbent firms, $\mu_{f}(\varphi)=g(\varphi) /\left[1-G\left(\varphi_{d f}^{*}\right)\right] \forall \varphi \geq \varphi_{d f}^{*}$, is determined by $e x$ ante probability of firm productivity based on successful entry. The ex ante probability of exporting to China is then $p_{f}^{x}=\frac{1-G\left(\varphi_{x f}^{*}\right)}{1-G\left(\varphi_{d f}^{*}\right)}$. Accordingly, the aggregate productivity levels for foreign domestic firms and exporters are defined as:

$$
\begin{gathered}
\tilde{\varphi}_{f}^{d}\left(\varphi_{d f}^{*}\right)=\left[\frac{1}{1-G\left(\varphi_{d f}^{*}\right)} \int_{\varphi_{d f}^{*}}^{\infty} \varphi^{\sigma-1} g(\varphi) d \varphi\right]^{\frac{1}{\sigma-1}}, \\
\tilde{\varphi}_{f}^{x}\left(\varphi_{x f}^{*}\right)=\left[\frac{1}{1-G\left(\varphi_{x f}^{*}\right)} \int_{\varphi_{x f}^{*}}^{\infty} \varphi^{\sigma-1} g(\varphi) d \varphi\right]^{\frac{1}{\sigma-1}} .
\end{gathered}
$$

Analogously to China, the total number of producing firms is denoted by $M_{f}$ and the mass of exporting firms is $M_{f}^{x}=p_{f}^{x} M_{f}$ in Foreign Country. However, the total number of firms competing in Foreign Country is $M_{f}+M_{c}^{s}+M_{c}^{x}$, which implies the mass of producing firms is not equal to the total varieties available to consumers in Foreign Country $\left(M_{f} \neq M_{c}^{s}+M_{c}^{x}+M_{f}\right)$. Similarly, the total mass of 
varieties available to consumers in China is $M_{c}^{d}+M_{f}^{x}$, which indicates the total varieties that produced in China is not equal to the total varieties available to the Chinese consumer $\left(M_{c} \neq M_{c}^{d}+M_{f}^{x}\right)$.

The construction of productivity averages in both regions (111)- -13 and (16)-(17) ) can also be used to express the average profit and revenue across different types of firms: $r_{c}^{s}\left(\tilde{\varphi}_{c}^{s}\right)$ and $\pi_{c}^{s}\left(\tilde{\varphi}_{c}^{s}\right)$ represent the average revenue and profit earned by Chinese pure exporters from sales in Foreign Country. Nevertheless, $r_{i}^{d}\left(\tilde{\varphi}_{i}^{d}\right)$ and $\pi_{i}^{d}\left(\tilde{\varphi}_{i}^{d}\right)$ describe the average revenue and profit obtained by domestic firms in their own country; similarly $r_{i}^{x}\left(\tilde{\varphi}_{i}^{x}\right)$ and $\pi_{i}^{x}\left(\tilde{\varphi}_{i}^{x}\right)$ depict the average export revenue and profit earned by domestic regular exporters. The overall average, across all types of firms, of combined revenue, earned from both markets, is thus given by:

$$
\begin{aligned}
& \bar{r}_{c}=p_{c}^{s} \sigma f w_{c}\left(\frac{\tilde{\varphi}_{c}^{s}}{\varphi_{s}^{*}}\right)^{\sigma-1}+p_{c}^{d} \sigma w_{c}\left[\left(f+f_{d}\right)\left(\frac{\tilde{\varphi}_{c}^{d}}{\varphi_{d}^{*}}\right)^{\sigma-1}+p_{c}^{x} f_{x}\left(\frac{\tilde{\varphi}_{c}^{x}}{\varphi_{x}^{*}}\right)^{\sigma-1}\right], \\
& \bar{r}_{f}=\sigma\left(f+f_{d}\right) w_{f}\left(\frac{\tilde{\varphi}_{f}^{d}}{\varphi_{d f}^{*}}\right)^{\sigma-1}+p_{f}^{x} \sigma f_{x} w_{f}\left(\frac{\tilde{\varphi}_{f}^{x}}{\varphi_{x f}^{*}}\right)^{\sigma-1} .
\end{aligned}
$$

The partitioning of firms by export status in both countries can be obtained if and only if $\tau^{\sigma-1} f<$ $f+f_{d}<\tau^{\sigma-1} f_{x}$, which requires $R_{f} P_{f}^{\sigma-1}=R_{c} P_{c}^{\sigma-1}$ is satisfied. That is, beachhead costs with variable export costs are relatively small to production costs plus the domestic trade barriers, while export trade costs must be above a domestic productivity threshold, based on $R_{f} P_{f}^{\sigma-1}=R_{c} P_{c}^{\sigma-1}$ is holding. Satisfying these conditions could make the model generate partitioning of the coexistence, within a narrowly defined industry, of pure exporters, domestic firms and regular exporters. More importantly, the holding of $R_{f} P_{f}^{\sigma-1}=R_{c} P_{c}^{\sigma-1}$ draws special attention. Substituting the total revenue $R_{i}$ with total labor income $R_{i}=w_{i} L$ and $w_{c}<w_{f}$ yields $P_{f}^{\sigma-1}<P_{c}^{\sigma-1}$ and $R_{f}>R_{c}$. That is, the price index in China, $P_{c}$, is high relative to the foreign price index, $P_{f}$, and Foreign Country has a lower true cost of living index and a higher utility level relative to China $\left(U_{f}>U_{c}\right)$. In other words, as a consequence of a very large proportion of processing trade, Chinese consumers are faced with higher prices while foreign consumers reap the benefits of cheap processed goods.

\subsection{Equilibrium Conditions}

The zero cutoff profit conditions in both countries imply a relationship between the average profit per firm and the cutoff productivity levels:

$$
\begin{array}{lll}
\pi_{c}^{s}\left(\varphi_{s}^{*}\right)=0 & \Longleftrightarrow & \pi_{c}^{s}\left(\tilde{\varphi}_{c}^{s}\right)=f w_{c} k\left(\varphi_{s}^{*}\right), \\
\pi_{c}^{d}\left(\varphi_{d}^{*}\right)=0 & \Longleftrightarrow & \pi_{c}^{d}\left(\tilde{\varphi}_{c}^{d}\right)=\left(f+f_{d}\right) w_{c} k\left(\varphi_{d}^{*}\right), \\
\pi_{c}^{x}\left(\varphi_{x}^{*}\right)=0 \quad \Longleftrightarrow \quad \pi_{c}^{x}\left(\tilde{\varphi}_{c}^{x}\right)=f_{x} w_{c} k\left(\varphi_{x}^{*}\right),
\end{array}
$$


where $k(\varphi)=\left[(\tilde{\varphi}(\varphi) / \varphi)^{\sigma-1}-1\right]$. The expression for the corresponding variables for foreign firms are defined analogously;

$$
\begin{array}{lll}
\pi_{f}^{d}\left(\varphi_{d f}^{*}\right)=0 & \Longleftrightarrow \quad \pi_{f}^{d}\left(\tilde{\varphi}_{f}^{d}\right)=\left(f+f_{d}\right) w_{f} k\left(\varphi_{d f}^{*}\right), \\
\pi_{f}^{x}\left(\varphi_{x f}^{*}\right)=0 & \Longleftrightarrow \quad \pi_{f}^{x}\left(\tilde{\varphi}_{f}^{x}\right)=f_{x} w_{f} k\left(\varphi_{x f}^{*}\right) .
\end{array}
$$

The zero cutoff profit conditions also imply that all other cutoff productivity levels can be written as a function of domestic cutoff productivity:

$$
\begin{aligned}
& \frac{r_{c}^{s}\left(\varphi_{s}^{*}\right)}{r_{c}^{d}\left(\varphi_{d}^{*}\right)}=\tau^{1-\sigma}\left(\frac{\varphi_{s}^{*}}{\varphi_{d}^{*}}\right)^{\sigma-1}=\frac{f}{f+f_{d}} \quad \Longleftrightarrow \quad \varphi_{s}^{*}=\varphi_{d}^{*} \tau\left(\frac{f}{f+f_{d}}\right)^{\frac{1}{\sigma-1}}, \\
& \frac{r_{c}^{x}\left(\varphi_{x}^{*}\right)}{r_{c}^{d}\left(\varphi_{d}^{*}\right)}=\tau^{1-\sigma}\left(\frac{\varphi_{x}^{*}}{\varphi_{d}^{*}}\right)^{\sigma-1}=\frac{f_{x}}{f+f_{d}} \quad \Longleftrightarrow \quad \varphi_{x}^{*}=\varphi_{d}^{*} \tau\left(\frac{f_{x}}{f+f_{d}}\right)^{\frac{1}{\sigma-1}}, \\
& \frac{r_{f}^{x}\left(\varphi_{x f}^{*}\right)}{r_{f}^{d}\left(\varphi_{d f}^{*}\right)}=\tau^{1-\sigma}\left(\frac{\varphi_{x f}^{*}}{\varphi_{d f}^{*}}\right)^{\sigma-1}=\frac{f_{x}}{f+f_{d}} \quad \Longleftrightarrow \quad \varphi_{x f}^{*}=\varphi_{d f}^{*} \tau\left(\frac{f_{x}}{f+f_{d}}\right)^{\frac{1}{\sigma-1}} .
\end{aligned}
$$

Hence, the average profit flow for a surviving firm in China and Foreign Country are, respectively,

$$
\begin{aligned}
\bar{\pi}_{c} & =p_{c}^{s} \pi_{c}^{s}\left(\tilde{\varphi}_{c}^{s}\right)+p_{c}^{d}\left(\pi_{c}^{d}\left(\tilde{\varphi}_{c}^{d}\right)+p_{c}^{x} \pi_{c}^{x}\left(\tilde{\varphi}_{c}^{x}\right)\right) \\
& =p_{c}^{s} f w_{c} k\left(\varphi_{s}^{*}\right)+p_{c}^{d}\left(\left(f+f_{d}\right) w_{c} k\left(\varphi_{d}^{*}\right)+p_{c}^{x} f_{x} w_{c} k\left(\varphi_{x f}^{*}\right)\right), \\
\bar{\pi}_{f} & =\pi_{f}^{d}\left(\tilde{\varphi}_{f}^{d}\right)+p_{f}^{x} \pi_{f}^{x}\left(\tilde{\varphi}_{f}^{x}\right), \\
& =\left(f+f_{d}\right) w_{f} k\left(\varphi_{d f}^{*}\right)+p_{f}^{x} f_{x} w_{f} k\left(\varphi_{x}^{*}\right),
\end{aligned}
$$

where all other cutoff productivity levels and fractions of exporting firms are implicitly defined as a function of domestic cutoff level using equations (18) - (20). These two equations thus identify the zero cutoff profit conditions for China and Foreign Country.

\subsection{Determination of the Equilibrium}

The potential entrants enter the industry until the expected value of entry, $V_{i}$, equals the sunk entry costs, $f_{e} w_{i}$. The expected value of entry $V_{i}$ is the ex ante probability of successful entry, $1-G\left(\varphi_{i}\right)$, multiplied by the expected profits of producing goods until death. Hence, the free entry conditions for China and Foreign Country are

$$
\begin{aligned}
& V_{c}=\frac{1-G\left(\varphi_{s}^{*}\right)}{\delta} \bar{\pi}_{c}=f_{e} w_{c}, \\
& V_{f}=\frac{1-G\left(\varphi_{d f}^{*}\right)}{\delta} \bar{\pi}_{f}=f_{e} w_{f},
\end{aligned}
$$

where $\bar{\pi}_{i}$ is the average firm profit from successful entry. In particular, some low-productivity Chinese firms fully export to Foreign Country, while some intermediate-productivity Chinese firms concentrate on domestic market. With the definition of weighted average productivity above, the free entry conditions in China and Foreign Country can be rewritten as a function solely of the zero profit productivity 
and parameters of the model:

$$
\begin{aligned}
& f_{e}=\frac{f}{\delta} J\left(\varphi_{s}^{*}\right)+\frac{f+f_{d}}{\delta} J\left(\varphi_{d}^{*}\right)+\frac{f_{x}}{\delta} J\left(\varphi_{x}^{*}\right), \\
& f_{e}=\frac{f+f_{d}}{\delta} J\left(\varphi_{d f}^{*}\right)+\frac{f_{x}}{\delta} J\left(\varphi_{x f}^{*}\right), \\
& J\left(\varphi_{s}^{*}\right)=\int_{\varphi_{s}^{*}}^{\varphi_{d}^{*}}\left[\left(\frac{\varphi}{\varphi_{s}^{*}}\right)^{\sigma-1}-1\right] g(\varphi) d \varphi, \quad J\left(\varphi_{i}^{*}\right)=\int_{\varphi_{i}^{*}}^{\infty}\left[\left(\frac{\varphi}{\varphi_{i}^{*}}\right)^{\sigma-1}-1\right] g(\varphi) d \varphi .
\end{aligned}
$$

Using the relationship between productivity cutoffs $(18)-(20)$, and noting that $J(\cdot)$ is a decreasing function, the above free entry conditions identify unique equilibrium values of domestic cutoffs for China and Foreign Country $\left(\varphi_{d}^{*}\right.$ and $\left.\varphi_{d f}^{*}\right)$. These in turn determine export productivity cutoffs $\left(\varphi_{s}^{*}, \varphi_{x}^{*}\right.$ and $\left.\varphi_{x f}^{*}\right)$ as well as average productivity levels and the ex ante successful entry and export probabilities. In addition, the increase in fixed production costs, $f$, fixed domestic trade costs, $f_{d}$, and fixed export $\operatorname{costs}, f_{x}$, raise the productivity cutoff levels $\varphi_{d}^{*}$ and $\varphi_{d f}^{*}$ in both regions. The higher fixed costs indicate that firms must draw a higher productivity to earn sufficient revenue to overcome these costs. On the other hand, raising these costs reduce the mass of goods produced, improve firms'ex post profitability, and therefore increases the probability of less productive firms surviving in the industry.

In a stationary equilibrium with constant mass of operating firms, the mass of successful new entrants must equal the mass of incumbents that die: $\left[1-G\left(\varphi_{i}^{*}\right)\right] M_{i}^{e}=\delta M_{i}$. Product variety in a destination is given by the total mass of sellers. Hence, the price index in China and Foreign Country is the CES aggregate of the prices of all of these goods:

$$
\begin{aligned}
& P_{c}=\left[M_{c}^{d} p_{c}^{d}\left(\tilde{\varphi}_{c}^{d}\right)^{1-\sigma}+M_{f}^{x} p_{f}^{x}\left(\tilde{\varphi}_{f}^{x}\right)^{1-\sigma}\right]^{\frac{1}{1-\sigma}}, \\
& P_{f}=\left[M_{f} p_{f}^{d}\left(\tilde{\varphi}_{f}^{d}\right)^{1-\sigma}+M_{c}^{x} p_{c}^{x}\left(\tilde{\varphi}_{c}^{x}\right)^{1-\sigma}+M_{c}^{s} p_{c}^{s}\left(\tilde{\varphi}_{c}^{s}\right)^{1-\sigma}\right]^{\frac{1}{1-\sigma}},
\end{aligned}
$$

where $M_{i}^{k}$ is the mass of operating firm choosing production mode $k$ in country $i$. Notice that $M_{c}^{s}$ denotes the varieties produced by Chinese pure exporters but only consumed in Foreign Country. As a result, the price indices vary across these two regions.

The comparison of industry cutoff productivity (7) and domestic productivity thresholds in China (8) and Foreign Country (14) reveals $\varphi_{s}^{*}<\varphi_{d}^{*}<\varphi_{d f}^{*}$. This implies that firms located in Foreign Country have better accesses to obtaining a productivity above any cutoff level, and that only more productive firms can survive. In other words, ex ante Chinese firms draw lower productivity levels relative to their counterpart in Foreign Country. The productivity cutoff level of surviving Foreign firms, $\varphi_{d f}^{*}$, is therefore higher than $\varphi_{s}^{*}$. Foreign firms face more severe competition both from Chinese pure and regular exporters compared to that faced by Chinese firms in its own market, result in $\varphi_{x}^{*}<\varphi_{x f}^{*}$. In particular, firms in Foreign Country with better productivity distribution is associated with higher productivity, a lower price index and a higher welfare per worker relative to that of China. These results fit the empirical feature that China is a technology inferior country relative to developed countries e.g. the U.S. 
The labor market clearing condition requires that, in both countries, total labor used for production and the investment (by new entrants) must equal the total labor endowment

$$
L=M_{i}^{e} f_{e}+M_{i}\left(\int l_{i}^{k}(\varphi) d \mu_{i}(\varphi)\right), \quad i \in\{c, f\}
$$

where $\mu_{i}(\varphi)$ is the ex post distribution of operating firms across productivity levels in country $i$, and $l_{i}^{k}$ is the optimal labor demand for a firm with productivity $\varphi$ using production mode $k$ in country $i$. The mass of producing firms, $M_{i}$, can be determined from the ratio of aggregate revenue, $R_{i}$, to average firm revenue:

$$
\begin{aligned}
& M_{c}=\frac{R_{c}}{\bar{r}_{c}}=\frac{L}{\sigma\left(p_{c}^{s} f\left(\frac{\tilde{\varphi}_{c}^{s}}{\varphi_{s}^{*}}\right)^{\sigma-1}+p_{c}^{d}\left[\left(f+f_{d}\right)\left(\frac{\tilde{\varphi}_{c}^{d}}{\varphi_{d}^{*}}\right)^{\sigma-1}+p_{c}^{x} f_{x}\left(\frac{\tilde{\varphi}_{c}^{x}}{\varphi_{x}^{*}}\right)^{\sigma-1}\right]\right)}, \\
& M_{f}=\frac{R_{f}}{\bar{r}_{f}}=\frac{L}{\sigma\left(\left(f+f_{d}\right)\left(\frac{\tilde{\varphi}_{f}^{d}}{\varphi_{d f}^{*}}\right)^{\sigma-1}+p_{f}^{x} f_{x}\left(\frac{\tilde{\varphi}_{f}^{x}}{\varphi_{x f}^{*}}\right)^{\sigma-1}\right)} .
\end{aligned}
$$

Other things equal, the rise in average productivity following the opening of trade reduces the mass of domestically produced varieties. The trade balance condition is derived from labor market clearing, free entry, zero-profit productivity cutoff conditions and the requirement that trade is balanced:

$$
r_{c}^{f}\left(\tilde{\varphi}_{c}^{x}\right) M_{c}^{x}+r_{c}^{s}\left(\tilde{\varphi}_{c}^{s}\right) M_{c}^{s}=r_{f}^{x}\left(\tilde{\varphi}_{f}^{x}\right) M_{f}^{x}
$$

To put it more simply, the total value of China's manufacturing export must equal the value of manufacturing import produced by foreign firms.

The equilibrium is referenced by a vector of variables in China and Foreign Country: $\left\{\varphi_{s}^{*}, \varphi_{d}^{*}, \varphi_{x}^{*}, \varphi_{d f}^{*}, \varphi_{x f}^{*}\right\}$. All other endogenous variables $\left(M_{c}, M_{f}, P_{c}, P_{f}\right)$ can be written as functions of these quantities such that the labor market is clearing, free entry and aggregate expenditure equations are satisfied in both countries and the balance trade condition holds. We showed in Appendix B.3 that there exists a unique equilibrium.

\section{Impact of Trade Liberalization}

The preceding analysis has shown that the presence of processing trade along with the fixed domestic trade costs and export entry costs can induce a partitioning of firms by export status, based on firm productivity. Nevertheless, this result is not exactly earth-shattering. The current model is well-suited to address several important issues concerning the impact of trade liberalization with the existence of processing trade and firm heterogeneity: Do all firms within a sector benefit from trade, or does the impact depend on a firm's productivity? How are the aggregate productivity and welfare affected in the presence of processing trade? What happens to the range of firm productivity levels? In particular, 
this model is much better suited to tackle several different mechanisms that would produce an increase in trade exposure and plausibly correspond to the observed decreases in trade costs over time or some specific policies to liberalized trade. The effects of such mechanisms are investigated: a decrease in either fixed or variable export trade costs and a falling in domestic trade costs. These three scenarios involve comparative statics of the open economy equilibrium with respect to $f_{x}, \tau$ and $f_{d}$. We show that trade liberalization in fixed export costs force the least productive Chinese pure exporters to exit, while simultaneously raises domestic productivity levels in both countries. Moreover, the increased exposure to trade in $\tau$ generates very similar result for the decrease in $f_{x}$. The only difference is that the industry cutoff productivity level has decreased in China. In addition, a more integrated domestic market forces the least productive Chinese pure exporters to exit and has an overall positive impact of welfare in both regions. In summary, all these changes unequivocally deliver welfare gains and nations always benefit from freer trade.

\subsection{Decrease in Fixed Export Trade Costs}

I first investigate the effects of a decrease in the fixed export costs $f_{x}$. Throughout the comparative static analysis, I haved used the old notation to describe the old equilibrium. I then added primes $\left({ }^{\prime}\right)$ to all variables and functions when they pertain to the new equilibrium with $f_{x}^{\prime}<f_{x}$.

Proposition 1. A decrease in fixed export trade costs forces the least efficient firms to exit and therefore generates productivity improvement in both regions. It also creates entry of new regular firms into the export markets in both countries.

For Proof: See Appendix C.1.

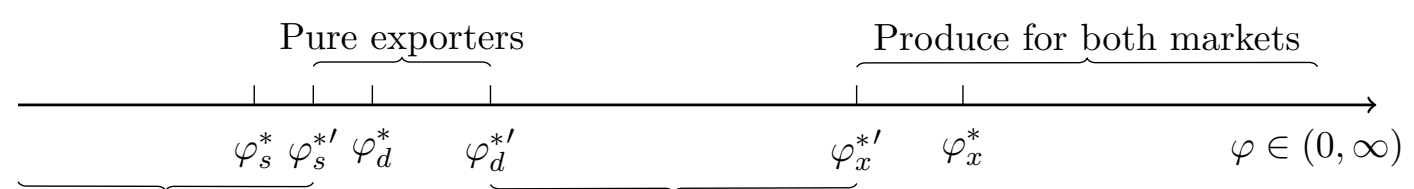

Firm exit

Produce for

the Chinese market only

Figure 4: The impact of falling $f_{x}$ on productivity cutoffs in China

Trade liberalization in foreign market access costs induces an increase in the industry cutoff productivity levels in both countries and a decrease in regular export levels. Falling export costs $f_{x}$ drives the least efficient pure exporters out of market $\varphi_{s}^{* \prime}>\varphi_{s}^{*}$. In particular, reductions in barriers to trade lead to all surviving Chinese pure exporters incurring revenue and profits $\operatorname{loss} r_{c}^{s \prime}(\varphi)<r_{c}^{s}(\varphi)$. The reduction in profits from the foreign market causes some low-efficient pure exporters that were previously marginal to exit the industry. As the low-productivity pure exporters exit, resources are reallocated toward higher-productivity firms. 
With respect to the regular firms, the increased exposure to trade improves the productivity thresholds of serving domestic markets: $\varphi_{d}^{* \prime}>\varphi_{d}^{*}$ and $\varphi_{d f}^{* \prime}>\varphi_{d f}^{*}$ in both countries. Notably, this causes the least productive Chinese regular firms with productivity levels between $\varphi_{d}^{*}$ and $\varphi_{d}^{* \prime}$ to no longer be able to earn positive profits in the domestic market, and hence force to engage in processing trade, while the least productive foreign firms $\left(\varphi_{d f}^{*} \leq \varphi<\varphi_{d f}^{*}\right)$ are forced to exit. Furthermore, all existing domestic regular firms in both regions relinquish a portion of their domestic revenue: $r_{i}^{d^{\prime}}(\varphi)<r_{i}^{d}(\varphi), i \in\{c, f\}$. On the other hand, the decreased export thresholds ( $\varphi_{i}^{x}$ decrease) generate entry of new firms into the export market. Regular firms which do not export with high $f_{x}$ are then able to serve the foreign market, and their combined sales increase with falling $f_{x}$. Firms that already exported prior to the change in $f_{x}$ not increase their combined revenue and profits. In general, trade liberalization therefore reallocates revenue and profits away from the least efficient firms that exit toward more productive firms that enter the regular export markets. The reallocations of revenue and profits generate an aggregate productivity improvement and an increase in welfare in both countries. Figure 4 graphically represents the changes in productivity cutoffs driven by falling $f_{x}$ in China.

\subsection{Decrease in Variable Trade Costs}

Proposition 2. Falling variable trade costs reduce the productivity cutoff of pure exporters and cause the entry of more inefficient firms in China. The regular export cutoff productivity levels decrease as well. On the contrary, declining iceberg costs induce an increase in the domestic cutoff productivity levels in both regions.

For Proof: See Appendix C.2.

\begin{tabular}{|c|c|c|c|c|c|}
\hline \multicolumn{3}{|c|}{ Pure exporters } & \multicolumn{3}{|c|}{ Produce for both markets } \\
\hline$\perp 1$ & $\perp$ & & & $\perp$ & \\
\hline$\varphi_{s}^{* \prime} \varphi_{s}^{*}$ & $\varphi_{d}^{*}$ & $\varphi_{d}^{* \prime}$ & & $\varphi_{x}^{*}$ & $\varphi \in(0, \infty)$ \\
\hline Firm exit & & & & & \\
\hline
\end{tabular}

Figure 5: The impact of falling $\tau$ on productivity cutoffs in China

A decrease in the variable trade costs from $\tau$ to $\tau^{\prime}$ distributes different effects to Chinese and foreign firms. The evolution of firms in Foreign Country follows the conventional pattern as outlined by Melitz (2003). The least productive foreign firms are forced to exit, and therefore the industrial productivity cutoff level rises $\varphi_{d f}^{*}>\varphi_{d f}^{*}$. In contrast, changes in $\tau$ shift down the export productivity cutoff level $\varphi_{x f}^{*}{ }^{\prime}<\varphi_{x f}^{*}$. The increased exposure to trade generates entry of new regular firms into the export market (that did not export with the higher $\tau$ ). All firms lose a portion of their domestic sales, so that the firms that do not export incur both a revenue and profit loss. The more productive firms 
that export more than make up for the loss of domestic sales with increased export sales, and the most productive firms among this group also increase their profits: $r_{f}^{d^{\prime}}(\varphi)+r_{f}^{x \prime}(\varphi)>r_{f}^{d}(\varphi)+r_{f}^{x}(\varphi)$.

On the other hand, the decline in variable trade costs distinctly impacts to the pure exporters and regular firms in China. Falling iceberg trade costs $\tau$ raise the domestic cutoff level: $\varphi_{d}^{* \prime}>\varphi_{d}^{*}$, and the aggregate domestic productivity in China. Regular firms previously producing with low productivity levels can no longer earn positive profits from regular production mode, and hence switch to processing trade regime instead of exiting the industry. Furthermore, it also causes the entry of more low-productive pure exporters in China. That is, the falling transport cost $\tau$ is particularly beneficial for them as it creates more export opportunities, offers greater revenue and profits, and pays fewer costs. As shown in Figure 5, this leads to more of the low-productive firms self-selecting into processing trade: $\varphi_{s}^{* \prime}<\varphi_{s}^{*}$. In other words, a fall in transport costs promotes processing activities in China. However, as more Chinese firms become pure exporters, a larger set of varieties produced by Chinese firms with productivity $\varphi \in\left[\varphi_{s}^{* \prime}, \varphi_{d}^{* \prime}\right)$ becomes unavailable to Chinese consumers.

To put it more simply, greater openness raises $\varphi_{d}^{*}$ and thus decreases locally produced varieties. Lower variable costs of trade produce an "anti-variety" effect, i.e. the range of consumed variety in China falls as trade becomes freer. On the contrary, Foreign Country experiences a "pro-variety effect", as a greater number of varieties manufactured by Chinese pure exporters becomes available to foreign consumers. Nevertheless, welfare always increases with trade freeness in both regions. Above all, the increased labor demand (by the less productive firms and new entrants) causes the real wage to increase. It therefore pulls more low-productive non-exporters switching into processing trade, as these firms could not afford to cover the entry costs of domestic market. In particular, falling iceberg costs and export trade barriers together help to explain the empirical feature that the export booms of China are driven by the entry of processing firms into the export market. As documented in Yu and Tian (2012); Defever and Riao (2012); Lemoine and Unal-Kesenci (2004) and Manova and Yu (2013), the accession to WTO substantially reduced the average tariff to $9 \%$ and dramatically increased the prevalence of processing trade in China, in which the share of pure exporters among all exporters increased from $30.36 \%$ to $40.59 \%$ in 2006 and constitutes one-half of China's total trade in 2000s.

\subsection{Decrease in Domestic Trade Cost}

Proposition 3. Falling domestic trade barriers raise the cutoff productivity level of pure exporters in China, while decreasing the productivity thresholds of serving the domestic market in both regions. The freer domestic trade also raises the export productivity cutoffs in both countries.

For Proof: See Appendix C.3. 


$\underbrace{\varphi_{\varphi_{s}^{*} \varphi_{s}^{* \prime}}^{\text {Pure exporters }}}_{\text {Firm exit }} \overbrace{\text { Produce for the Chinese market only }}^{\varphi_{\varphi_{d}^{* \prime} \varphi_{d}^{*}}}$

Figure 6: The impact of falling $f_{d}$ on productivity cutoffs in China

Lowering domestic entry costs $f_{d}$ raises the industry cutoff productivity in China $\varphi_{s}^{* \prime}>\varphi_{s}^{*}$, and thus forces the least efficient pure exporters to exit. The falling costs of entry into the domestic market also forces all existing Chinese pure exporters to lose a portion of revenue obtained from Foreign Country: $r_{c}^{s^{\prime}}(\varphi)<r_{c}^{s}(\varphi), \forall \in \varphi\left[\varphi_{s}^{*}, \varphi_{d}^{*}\right)$. Conversely, falling domestic trade barriers decrease the domestic cutoff productivity levels in both countries. In particular, the decline in domestic trade costs in China substantially reduces the barriers of serving the domestic market, which creates the entry of new domestic firms. The previously relative efficient pure exporters that were not able to pursue regular production mode are capable of engaging in domestic trade with lower $f_{d}$. In addition, these new domestic producers benefit from the more integrated domestic market as their revenue and profits increase. However, the successful entry of less productive pure exporters into the domestic market contributes to an aggregate domestic productivity loss. Moreover, the factors of increased industry cutoff productivity level and decreased domestic productivity threshold in China indicate that more Chinese firms are operating in regular production mode, and thus the competition in the domestic market is intensified. On the contrary, as fewer Chinese firms engage in processing trade, fewer varieties are manufactured by Chinese pure exporters, which, in turn, result in fewer varieties being supplied to foreign consumers.

Another way to gain insight into the impact of falling domestic barriers comes from the consumption side. A falling in domestic costs decreases the domestic cutoff productivity levels and therefore reduces the average profits of existing regular firms in both regions. The lower profit levels, in turn, imply an increase in domestic variety. The incresing product variety and the decreasing aggregate domestic productivity oppositely affect welfare. The appendix C.3.1 shows that the welfare change is positive and hence that the expanding product variety effect dominates that of the lower aggregate domestic productivity levels. This yields the reasonable property that lower domestic trade costs have an overall positive impact on welfare. In other words, if the domestic impediments were to hasten, it could alleviate our reliance on processing trade and help us avoid sticking in the low-valued added chain. Figure 6 helps to visualize the effects of trade liberalization in $f_{d}$ on all types of firms' productivity cutoffs in China.

On the other hand, the decrease from $f_{d}$ to $f_{d}{ }^{\prime}$ induces an increase in the cutoff productivity 
levels of regular exporters $\left(\varphi_{c}^{x}, \varphi_{f}^{x} \uparrow\right)^{9}$, The more intense entry following from the decreased domestic productivity thresholds in both countries enhances domestic product market competition and therefore raises the equilibrium exporting productivity levels. In other words, the productivity of survival is lowered while the exporting cutoff increases in China when facing domestic market integration.

The falling of domestic trade costs delivers very deep policy implications to China. Empirical evidences (Wong, 2012; Naughton, 2000) from China have documented that China has a very segmented domestic market; domestic firms incur domestic barriers to serve the local market. Some other studies have demonstrated that the internal market fragmentation promotes China's trade performance. Less efficient Chinese firms, which are not able to overcome such costs, engage in processing trade as pure exporters to full sell their output in foreign countries. That is, pure exporters enter the international market as an alternative way to pursue economies of scale. In other words, the factors of the server fragmented Chinese market teamed with the creation of processing trade distort Chinese firms export performances, which not only generate a large scale of pure exporters but also contribute to the rapid expansion of China's export. Moreover, these elements also illustrate a cluster of processing trade in eastern and southern China and coastal region prosperity.

Nevertheless, the highly fragmented domestic market has led to many Chinese firms only engaging in processing trade and getting supplied OEM (Original Equipment Manufacturing) products for the global buyers, but not able to establish a position in the international market for innovative and high-valued added products. Although local protection measures may help lift local economies in the short term, the distorted national market has spawned problems such as higher operation costs and overcapacity in the wider economy, undermining the economies of scale of China's huge market. Consequently, clearing domestic market barriers, coupled with reducing export reliance on processing trade, could allow the most productive ones to thrive, facilitate technology diffusion, improve productivity and ultimately increase the competitiveness of firms and growth in China. To this end, our model offers a theoretical basis for constructing an integrated Chinese domestic market. In particular, the removal of regional blockades across the country to build a unified and open market system can allow productivity to play a decisive role in allocating resources, and hence bring aggregate productivity growth when facing trade liberalization. Furthermore, the results and intuitions presented here indicate that gains from more liberalized trade could be larger for the more integrated internal market. This implies that China would respond to more export opportunities resulting from falling trad barriers if the government can unify

\footnotetext{
${ }^{9}$ Melitz (2003) states that there is a transitional issue associated with the exporting status of firms with productivity level between $\varphi_{c}^{x}$ and $\varphi_{c}^{x \prime}$. The loss of export sales to counterpart (from $r_{c}^{x}(\varphi)$ down to the $r_{c}^{x \prime}(\varphi)$ ) is such that firms entering with productivity levels between $\varphi_{c}^{x}$ and $\varphi_{c}^{x \prime}$ will not export as the lower variable profit $\frac{r_{c}^{x \prime}(\varphi)}{\sigma}$ no longer covers the amortized portion of the entry cost $f_{x}$. On the other hand, incumbent firms with productivity level in this range have already incurred the sunk entry cost of export and have no reason to exit the export market until they are hit with the bad shock and exit the industry. Eventually, all these incumbent firms exit and no firm with a productivity level in that range will export once the new steady state equilibrium is attained.
} 
the domestic market and liberalize domestic trade. The sooner a well-developed modern market system is established, the higher the aggregate productivity would likely be, and the smoother the transition.

\section{Conclusion}

Firm-level export patterns in China are different from those in developed countries and they may seem to be at odds with existing literature. Nevertheless, this can be explained by isolating processing trade from the regular export behavior in the context of heterogeneous firms literature. In particular, we have incorporated pure exporters into a single sector of Melitz (2003) model to explain how the pattern of trade in China is determined by the interaction of trade barriers and the large scale of processing trade. This model captures the existence of pure exporters and their infeiror productivity. It further explains how trade liberalization affect the aggregate productivity, welfare and export performances of Chinese firms.

In other words, this paper has described and analyzed a fundamental issue of coexistence, even within the same industry of exporters, pure exporters and non-exporters. The paper shows how the presence of processing trade alongside of the domestic trade costs drastically affect how the impact of trade is distributed across different types of firms. The less efficient firms behave as pure exporters, the moderate productive firms concentrate on the domestic market while the most efficient ones benefit from trade in revenues and profits. More importantly, our analysis reveal that increases in a country's exposure to trade unequivocally engender welfare gains, however, the domestic market distortion could impede firms' performances and hinder the aggregate productivity improvement. Furthermore, the model highlights that trade-induced reallocation effect of export which may generate aggregate productivity growth does not work effected in industries where processing trade is pervasive.

The recognition in the nature of firm heterogeneity is important because it will generate new insights concerning the current trade pattern and growth. Exporting is especially considered as an engine of growth in China. Processing trade does, indeed, have a significant positive effect on labor employment and it substantially utilizes our comparative advantage in labor intensive products. However, the long-run benefits associated with trade still depends on the productivity improvement. It is therefor imperative to have a model that can look into the costs and benefits of export processing and predict the impact of trade policies on various types of firms. Consequently, a deeper understanding of the factors that drive firms' export success will facilitate the design of policies that promote trade and ultimately growth in China. Interesting areas for future research include investigating the impact of trade liberalization on foreign-owned, private firms and state-own enterprises separately and empirically testing of our model's theoretical predictions. In addition, further quantitative analysis of the effect of trade liberalization on wages and welfare in both China and other countries would be interesting. 


\section{References}

Aw, B. Y., Chung, S., and Roberts, M. J. (2002). Productivity, output, and failure: A comparison of taiwanese and korean manufacturers. NBER Working Papers 8766, National Bureau of Economic Research, Inc.

Baldwin, R. E. and Forslid, R. (2010). Trade liberalization with heterogeneous firms. Review of Development Economics, 14(2):161-176.

Baldwin, R. E. and Okubo, T. (2014). International trade, offshoring and heterogeneous firms. Review of International Economics, 22(1):59-72.

Bernard, A. B., Eaton, J., Jensen, J. B., and Kortum, S. (2003). Plants and productivity in international trade. American Economic Review, 93(4):1268-1290. Cited By (since 1996): 199.

Bernard, A. B. and Jensen, J. B. (1994). Exporters, Jobs and Wages in U.S. Manufacturing: 1976-1987. Working papers 95-7, Massachusetts Institute of Technology (MIT), Department of Economics.

Bernard, A. B. and Jensen, J. B. (1999). Exceptional exporter performance: cause, effect, or both? Journal of International Economics, 47(1):1-25.

Bernard, A. B., Jensen, J. B., Redding, S. J., and Schott, P. K. (2011). The empirics of firm heterogeneity and international trade. Technical report, National Bureau of Economic Research.

Bernard, A. B., Redding, S. J., and Schott, P. K. (2007). Comparative advantage and heterogeneous firms. The Review of Economic Studies, 74(1):31-66.

Dai, M., Maitra, M., and Yu, M. (2011). Unexceptional exporter performance in china? the role of processing trade. Working Paper.

Defever, F. and Riao, A. (2012). China's Pure Exporter Subsidies. CEP Discussion Papers dp1182, Centre for Economic Performance, LSE.

Demidova, S. (2008). Productivity improvements and falling trade costs: Boon or bane?*. International Economic Review, 49(4):1437-1462.

Demidova, S. and Rodríguez-Clarez, A. (2011). The simple analytics of the melitz model in a small open economy. Technical report, National Bureau of Economic Research.

Dixit, A. K. and Stiglitz, J. E. (1975). Monopolistic competition and optimum product diversity. Technical report.

Eaton, J., Kortum, S., and Kramarz, F. (2011). An anatomy of international trade: Evidence from french firms. Econometrica, 79(5):1453-1498. 
FAN\&, H., Edwin, L., et al. (2013). A model of trade with ricardian comparative advantage and intra\&sectoral firm heterogeneity.

Fan, H., Lai, E. L.-C., and Qi, H. S. (2013). A Model of Trade with Ricardian Comparative Advantage and Intra-sectoral Firm Heterogeneity. CESifo Working Paper Series No. 3634, (1).

Fernandes, A. P. and Tang, H. (2013). Scale, scope, and trade dynamics of export processing plants. Working paper dated Nov 23, 2012, (1).

Fu, X. (2011). Processing trade, fdi and the exports of indigenous firms: Firm-level evidence from technology-intensive industries in china. Oxford Bulletin of Economics and Statistics, 73(6):792-817.

Fu, X. and Gao, Y. (2007). Export processing zones in china: A survey. Geneva: International Labour Organization.

Gao, B. and Tvede, M. (2013). Heterogeneous fixed export cost: Explaining the existence of export-only firms.

Guriev, S., Yakovlev, E., and Zhuravskaya, E. (2007). Inter-Regional Trade and Lobbying. Working Papers w0100, Center for Economic and Financial Research (CEFIR).

Helpman, E., Melitz, M. J., and Yeaple, S. R. (2004). Export Versus FDI with Heterogeneous Firms. American Economic Review, 94(1):300-316.

International Labor Organization (2007). Export Processing Zones: EPZ Employment Statistics. International Labor Organization, (1).

Lemoine, F. (2010). Past successes and new challenges: China's foreign trade at a turning point. China 83 World Economy, 18(3):1-23.

Lemoine, F. and Unal-Kesenci, D. (2004). Assembly Trade and Technology Transfer: The Case of China. World Development, 32(5):829-850.

Li, C. and Yin, X. (2009). Chinese export firms' productivity paradox and its explanations. Finance and Trade Economics, 11.

Lu, D. (2010). Exceptional exporter performance? evidence from chinese manufacturing firms. Manuscript, University of Chicago.

Lu, J., Lu, Y., and Tao, Z. (2010). Exporting behavior of foreign affiliates: Theory and evidence. Journal of International Economics, 81(2):197 - 205.

Lu, J., Lu, Y., and Tao, Z. (2014). Pure exporter: Theory and evidence from china. The World Economy, pages n/a-n/a. 
Ma, A. C., Van Assche, A., and Hong, C. (2009). Global production networks and china's processing trade. Journal of Asian Economics, 20(6):640-654.

Ma, Y., Tang, H., and Zhang, Y. (2014). Factor Intensity, product switching, and productivity: Evidence from Chinese exporters. Journal of International Economics, 92(2):349-362.

Manova, K. (2013). Credit constraints, heterogeneous firms, and international trade. The Review of Economic Studies, 80(2):711-744.

Manova, K. and Yu, Z. (2013). Firms and credit constraints along the global value chain: Processing trade in china. NBER WORKING PAPER SERIES.

McCallum, J. K. (2011). Export processing zones: comparative data from China, Honduras, Nicaragua, and South Africa. ILO.

Melitz, M. J. (2003). The impact of trade on intra-industry reallocations and aggregate industry productivity. Econometrica, 71(6):1695-1725.

Melitz, M. J. and Redding, S. J. (2012). Heterogeneous firms and trade. Technical report, National Bureau of Economic Research.

Melitz, M. J. and Trefler, D. (2012). Gains from trade when firms matter. The Journal of Economic Perspectives, pages 91-118.

Naughton, B. (2000). How much can regional integration do to unify china's markets?

Ottaviano, G., Melitz, M. J., and Mayer, T. (2011). Market size, competition, and the product mix of exporters. Sciences Po publications info:hdl:2441/c8dmi8nm4pd, Sciences Po.

Pflüger, M. and Russek, S. (2013). 12 heterogeneous firms, trade, and economic policy: Insights from a simple two-sector model. Firms in the International Economy: Firm Heterogeneity Meets International Business, page 369.

Redding, S. J. (2010). Theories of heterogeneous firms and trade. Technical report, National Bureau of Economic Research.

Wong, A. (2012). Measuring trade barriers: An application to china's domestic trade. Manuscript, University of Chicago.

World Trade Organization (2008). The WTO launches World Trade Report 2008: Trade in a Globalizing World. Geneva:World Trade Organization, (1).

Yeaple, S. R. (2009). Firm heterogeneity and the structure of U.S. multinational activity. Journal of International Economics, 78(2):206-215. 
Yu, M. and Tian, W. (2012). Chinas firm-level processing trade: Trends, characteristics, and productivity. Rebalancing and Sustaining Growth in China, Australian National University E-press, pages pp.111-148.

Zhang, J., Li, Y., and Liu, Z. (2009). Does export increase the productivity of enterprises in china? empirical evidence from chinas domestic manufacturing enterprises: 1999-2003. Management World, $12: 11-26$. 


\section{A Appendix: Equilibrium Conditions}

\section{A.1 Derivation of Average Revenue}

Average revenue of a Chinese firm can be determined as follows:

$$
\begin{aligned}
& \bar{r}_{c}=p_{c}^{s} r_{c}^{s}\left(\tilde{\varphi}_{c}^{s}\right)+p_{c}^{d}\left(r_{c}^{d}\left(\tilde{\varphi}_{c}^{d}\right)+p_{c}^{x} r_{c}^{x}\left(\tilde{\varphi}_{c}^{x}\right)\right) \\
& =p_{c}^{s} \int_{\varphi_{s}^{*}}^{\varphi_{d}^{*}} \frac{r_{c}^{s}(\varphi) g(\varphi)}{G\left(\varphi_{d}^{*}\right)-G\left(\varphi_{s}^{*}\right)} d \varphi+p_{c}^{d}\left(\int_{\varphi_{d}^{*}}^{\infty} \frac{r_{c}^{d}(\varphi) g(\varphi)}{1-G\left(\varphi_{d}^{*}\right)} d \varphi+p_{c}^{x} \int_{\varphi_{x}^{*}}^{\infty} \frac{r_{c}^{x}(\varphi) g(\varphi)}{1-G\left(\varphi_{x}^{*}\right)} d \varphi\right) \\
& =p_{c}^{s} \int_{\varphi_{s}^{*}}^{\varphi_{d}^{*}} \sigma f w_{c}\left(\frac{\varphi}{\varphi_{s}^{*}}\right)^{\sigma-1} \frac{g(\varphi)}{G\left(\varphi_{d}^{*}\right)-G\left(\varphi_{s}^{*}\right)} d \varphi \\
& +p_{c}^{d}\left(\int_{\varphi_{d}^{*}}^{\infty} \sigma\left(f+f_{d}\right) w_{c}\left(\frac{\varphi}{\varphi_{d}^{*}}\right)^{\sigma-1} \frac{g(\varphi)}{1-G\left(\varphi_{d}^{*}\right)} d \varphi+p_{c}^{x} \int_{\varphi_{x}^{*}}^{\infty} \sigma f_{x} w_{c}\left(\frac{\varphi}{\varphi_{x}^{*}}\right)^{\sigma-1} \frac{g(\varphi)}{1-G\left(\varphi_{x}^{*}\right)} d \varphi\right) \\
& =p_{c}^{s} \sigma f w_{c}\left(\frac{1}{\varphi_{s}^{*}}\right)^{\sigma-1} \underbrace{\int_{\varphi_{s}^{*}}^{\varphi_{d}^{*}} \frac{\varphi^{\sigma-1} g(\varphi)}{G\left(\varphi_{d}^{*}\right)-G\left(\varphi_{s}^{*}\right)} d \varphi}_{\left(\tilde{\varphi}_{c}^{s}\right)^{\sigma-1}} \\
& +p_{c}^{d} w_{c} \sigma(\left(f+f_{d}\right)\left(\frac{1}{\varphi_{d}^{*}}\right)^{\sigma-1} \underbrace{\int_{\varphi_{d}^{*}}^{\infty} \frac{\varphi^{\sigma-1} g(\varphi)}{1-G\left(\varphi_{d}^{*}\right)} d \varphi}_{\left(\tilde{\varphi}_{c}^{d}\right)^{\sigma-1}}+p_{c}^{x} f_{x}\left(\frac{1}{\varphi_{x}^{*}}\right)^{\sigma-1} \underbrace{\int_{\varphi_{x}^{*}}^{\infty} \frac{\varphi^{\sigma-1} g(\varphi)}{1-G\left(\varphi_{x}^{*}\right)} d \varphi}_{\left(\tilde{\varphi}_{c}^{x}\right)^{\sigma-1}}) \\
& =p_{c}^{s} \sigma f w_{c}\left(\frac{\tilde{\varphi}_{c}^{s}}{\varphi_{s}^{*}}\right)^{\sigma-1}+p_{c}^{d} \sigma w_{c}\left[\left(f+f_{d}\right)\left(\frac{\tilde{\varphi}_{c}^{d}}{\varphi_{d}^{*}}\right)^{\sigma-1}+p_{c}^{x} f_{x}\left(\frac{\tilde{\varphi}_{c}^{x}}{\varphi_{x}^{*}}\right)^{\sigma-1}\right],
\end{aligned}
$$

which depends solely on the productivity cutoffs, $\varphi_{s}^{*}, \varphi_{d}^{*}$ and $\varphi_{x}^{*}$, and parameters. The average revenue of a foreign firm can be derived as the similar way

$$
\bar{r}_{f}=\sigma\left(f+f_{d}\right) w_{f}\left(\frac{\tilde{\varphi}_{f}^{d}}{\varphi_{d f}^{*}}\right)^{\sigma-1}+p_{f}^{x} \sigma f_{x} w_{f}\left(\frac{\tilde{\varphi}_{f}^{x}}{\varphi_{x f}^{*}}\right)^{\sigma-1} .
$$

\section{A.2 Derivation of Free Entry Conditions}

Combining the ZCP1 and FE1, and use the definition of aggregate average productivity from (11) -(13), we obtain a single equation that determines the productivity cutoff in China

$$
\begin{aligned}
f_{e} w_{c} & =\frac{1-G\left(\varphi_{s}^{*}\right)}{\delta}\left\{p_{c}^{s} \pi_{c}^{s}\left(\tilde{\varphi}_{c}^{s}\right)+p_{c}^{d}\left(\pi_{c}^{d}\left(\tilde{\varphi}_{c}^{d}\right)+p_{c}^{x} \pi_{c}^{x}\left(\tilde{\varphi}_{c}^{x}\right)\right)\right\} \\
& =\frac{1-G\left(\varphi_{s}^{*}\right)}{\delta} w_{c}\left\{p_{c}^{s} f\left[\left(\frac{\tilde{\varphi}_{c}^{s}}{\varphi_{s}^{*}}\right)^{\sigma-1}-1\right]\right. \\
& \left.+p_{c}^{d}\left(\left(f+f_{d}\right)\left[\left(\frac{\tilde{\varphi}_{c}^{d}}{\varphi_{d}^{*}}\right)^{\sigma-1}-1\right]+p_{c}^{x} f_{x}\left[\left(\frac{\tilde{\varphi}_{c}^{x}}{\varphi_{x}^{*}}\right)^{\sigma-1}-1\right]\right)\right\}
\end{aligned}
$$

wage $w_{c}$ cancel out from both sides

$$
f_{e}=\frac{1-G\left(\varphi_{s}^{*}\right)}{\delta} \frac{G\left(\varphi_{d}^{*}\right)-G\left(\varphi_{s}^{*}\right)}{1-G\left(\varphi_{s}^{*}\right)} f\left[\left(\frac{\tilde{\varphi}_{c}^{s}}{\varphi_{s}^{*}}\right)^{\sigma-1}-1\right]
$$




$$
\begin{aligned}
& +\frac{1-G\left(\varphi_{s}^{*}\right)}{\delta} \frac{1-G\left(\varphi_{d}^{*}\right)}{1-G\left(\varphi_{s}^{*}\right)}\left(f+f_{d}\right)\left[\left(\frac{\tilde{\varphi}_{c}^{d}}{\varphi_{d}^{*}}\right)^{\sigma-1}-1\right] \\
& +\frac{1-G\left(\varphi_{s}^{*}\right)}{\delta} \frac{1-G\left(\varphi_{d}^{*}\right)}{1-G\left(\varphi_{s}^{*}\right)} \frac{1-G\left(\varphi_{x}^{*}\right)}{1-G\left(\varphi_{d}^{*}\right)} f\left[\left(\frac{\tilde{\varphi}_{c}^{x}}{\varphi_{x}^{*}}\right)^{\sigma-1}-1\right] \\
& =\frac{f}{\delta}\left(G\left(\varphi_{d}^{*}\right)-G\left(\varphi_{s}^{*}\right)\right) \tilde{\varphi}_{c}^{s^{\sigma-1}} \tilde{\varphi}_{s}^{*^{1-\sigma}}-\frac{f}{\delta}\left(G\left(\varphi_{d}^{*}\right)-G\left(\varphi_{s}^{*}\right)\right) \\
& +\frac{f+f_{d}}{\delta}\left(1-G\left(\varphi_{d}^{*}\right)\right) \tilde{\varphi}_{c}^{d^{\sigma-1}} \tilde{\varphi}_{d}^{*^{1-\sigma}}-\frac{f+f_{d}}{\delta}\left(1-G\left(\varphi_{d}^{*}\right)\right) \\
& +\frac{f_{x}}{\delta}\left(1-G\left(\varphi_{x}^{*}\right)\right) \tilde{\varphi}_{c}^{x^{\sigma-1}} \tilde{\varphi}_{x}^{*^{1-\sigma}}-\frac{f_{x}}{\delta}\left(1-G\left(\varphi_{x}^{*}\right)\right) \\
& =\frac{f}{\delta}\left(G\left(\varphi_{d}^{*}\right)-G\left(\varphi_{s}^{*}\right)\right) \varphi_{s}^{*^{1-\sigma}} \frac{1}{G\left(\varphi_{d}^{*}\right)-G\left(\varphi_{s}^{*}\right)} \int_{\varphi_{s}^{*}}^{\varphi_{d}^{*}} \varphi^{\sigma-1} g(\varphi) d \varphi-\frac{f}{\delta} \int_{\varphi_{s}^{*}}^{\varphi_{d}^{*}} g(\varphi) d \varphi \\
& +\frac{f+f_{d}}{\delta}\left(1-G\left(\varphi_{d}^{*}\right)\right) \varphi_{d}^{*^{1-\sigma}} \frac{1}{1-G\left(\varphi_{d}^{*}\right)} \int_{\varphi_{d}^{*}}^{\varphi^{\sigma-1}} g(\varphi) d \varphi-\frac{f+f_{d}}{\delta} \int_{\varphi_{d}^{*}}^{\infty} g(\varphi) d \varphi \\
& +\frac{f_{x}}{\delta}\left(1-G\left(\varphi_{x}^{*}\right)\right) \varphi_{x}^{*^{1-\sigma}} \frac{1}{1-G\left(\varphi_{x}^{*}\right)} \int_{\varphi_{x}^{*}}^{\infty} \varphi^{\sigma-1} g(\varphi) d \varphi-\frac{f_{x}}{\delta} \int_{\varphi_{x}^{*}}^{\infty} g(\varphi) d \varphi \\
& =\frac{f}{\delta} \int_{\varphi_{s}^{*}}^{\varphi_{d}^{*}} \varphi_{s}^{*^{1-\sigma}} \varphi^{\sigma-1} g(\varphi) d \varphi-\frac{f}{\delta} \int_{\varphi_{s}^{*}}^{\varphi_{d}^{*}} g(\varphi) d \varphi \\
& +\frac{f+f_{d}}{\delta} \int_{\varphi_{d}^{*}}^{\infty} \varphi_{d}^{*^{1-\sigma}} \varphi^{\sigma-1} g(\varphi) d \varphi-\frac{f+f_{d}}{\delta} \int_{\varphi_{d}^{*}}^{\infty} g(\varphi) d \varphi \\
& +\frac{f_{x}}{\delta} \int_{\varphi_{x}^{*}}^{\infty} \varphi_{x}^{*^{1-\sigma}} \varphi^{\sigma-1} g(\varphi) d \varphi-\frac{f_{x}}{\delta} \int_{\varphi_{x}^{*}}^{\infty} g(\varphi) d \varphi \\
& =\frac{f}{\delta} \int_{\varphi_{s}^{*}}^{\varphi_{d}^{*}}\left[\left(\frac{\varphi}{\varphi_{s}^{*}}\right)^{\sigma-1}-1\right] g(\varphi) d \varphi+\frac{f+f_{d}}{\delta} \int_{\varphi_{d}^{*}}^{\infty}\left[\left(\frac{\varphi}{\varphi_{d}^{*}}\right)^{\sigma-1}-1\right] g(\varphi) d \varphi \\
& +\frac{f_{x}}{\delta} \int_{\varphi_{x}^{*}}^{\infty}\left[\left(\frac{\varphi}{\varphi_{x}^{*}}\right)^{\sigma-1}-1\right] g(\varphi) d \varphi \\
& \hline
\end{aligned}
$$

where

$$
\begin{aligned}
& J\left(\varphi_{s}^{*}\right)=\int_{\varphi_{s}^{*}}^{\varphi_{d}^{*}}\left[\left(\frac{\varphi}{\varphi_{s}^{*}}\right)^{\sigma-1}-1\right] g(\varphi) d \varphi, \\
& J\left(\varphi_{d}^{*}\right)=\int_{\varphi_{d}^{*}}^{\infty}\left[\left(\frac{\varphi}{\varphi_{d}^{*}}\right)^{\sigma-1}-1\right] g(\varphi) d \varphi, \\
& J\left(\varphi_{x}^{*}\right)=\int_{\varphi_{x}^{*}}^{\infty}\left[\left(\frac{\varphi}{\varphi_{x}^{*}}\right)^{\sigma-1}-1\right] g(\varphi) d \varphi .
\end{aligned}
$$

Similarly, combining the ZCP2 and FE2, and use the definition of aggregate average productivity from $(16)$ - (17), we obtain a single equation that determines the productivity cutoff in Foreign Country

$$
\begin{aligned}
f_{e} w_{f} & =\frac{1-G\left(\varphi_{d f}^{*}\right)}{\delta}\left\{\pi_{f}^{d}\left(\tilde{\varphi}_{f}^{d}\right)+p_{f}^{x} \pi_{f}^{x}\left(\tilde{\varphi}_{f}^{x}\right)\right\} \\
& =\frac{1-G\left(\varphi_{d f}^{*}\right)}{\delta} w_{f}\left\{\left(f+f_{d}\right)\left[\left(\frac{\tilde{\varphi}_{f}^{d}}{\varphi_{d f}^{*}}\right)^{\sigma-1}-1\right]+p_{f}^{x} f_{x}\left[\left(\frac{\tilde{\varphi}_{f}^{x}}{\varphi_{x f}^{*}}\right)^{\sigma-1}-1\right]\right\}
\end{aligned}
$$

wage $w_{f}$ cancel out from both sides

$$
f_{e}=\frac{1-G\left(\varphi_{d f}^{*}\right)}{\delta}\left(f+f_{d}\right)\left(\varphi_{d f}^{*}\right)^{1-\sigma}\left(\tilde{\varphi}_{f}^{d}\right)^{\sigma-1}-\frac{f+f_{d}}{\delta}\left(1-G\left(\varphi_{d f}^{*}\right)\right)
$$




$$
\begin{aligned}
& +\frac{1-G\left(\varphi_{d f}^{*}\right)}{\delta} \frac{1-G\left(\varphi_{x f}^{*}\right)}{1-G\left(\varphi_{d f}^{*}\right)} f_{x}\left[\left(\frac{\tilde{\varphi}_{f}^{x}}{\varphi_{x f}^{*}}\right)^{\sigma-1}-1\right] \\
& =\frac{f+f_{d}}{\delta}\left(1-G\left(\varphi_{d f}^{*}\right)\right)\left(\varphi_{d f}^{*}\right)^{1-\sigma} \frac{1}{1-G\left(\varphi_{d f}^{*}\right)} \int_{\varphi_{d f}^{*}}^{\infty} \varphi^{\sigma-1} g(\varphi) d \varphi-\frac{f+f_{d}}{\delta} \int_{\varphi_{d f}^{*}}^{\infty} g(\varphi) d \varphi \\
& +\frac{f_{x}}{\delta}\left(1-G\left(\varphi_{x f}^{*}\right)\right)\left(\varphi_{x f}^{*}\right)^{1-\sigma}\left(\tilde{\varphi}_{f}^{x}\right)^{\sigma-1}-\frac{f_{x}}{\delta}\left(1-G\left(\varphi_{x f}^{*}\right)\right) \\
& =\frac{f+f_{d}}{\delta} \int_{\varphi_{d f}^{*}}^{\infty}\left(\frac{\varphi}{\varphi_{d f}^{*}}\right)^{\sigma-1} g(\varphi) d \varphi-\frac{f+f_{d}}{\delta} \int_{\varphi_{d f}^{*}}^{\infty} g(\varphi) d \varphi \\
& +\frac{f_{x}}{\delta}\left(1-G\left(\varphi_{x f}^{*}\right)\right)\left(\varphi_{x f}^{*}\right)^{1-\sigma} \frac{1}{1-G\left(\varphi_{x f}^{*}\right)} \int_{\varphi_{x f}^{*}}^{\infty} \varphi^{\sigma-1} g(\varphi) d \varphi-\frac{f_{x}}{\delta} \int_{\varphi_{x f}^{*}}^{\infty} g(\varphi) d \varphi \\
& =\frac{f+f_{d}}{\delta} \int_{\varphi_{d f}^{*}}^{\infty}\left[\left(\frac{\varphi}{\varphi_{d f}^{*}}\right)^{\sigma-1}-1\right] g(\varphi) d \varphi+\frac{f_{x}}{\delta} \int_{\varphi_{x f}^{*}}^{\infty}\left[\left(\frac{\varphi}{\varphi_{x f}^{*}}\right)^{\sigma-1}-1\right] g(\varphi) d \varphi \\
& =\frac{f+f_{d}}{\delta} J\left(\varphi_{d f}^{*}\right)+\frac{f_{x}}{\delta} J\left(\varphi_{x f}^{*}\right),
\end{aligned}
$$

where

$$
\begin{aligned}
& J\left(\varphi_{d f}^{*}\right)=\int_{\varphi_{d f}^{*}}^{\infty}\left[\left(\frac{\varphi}{\varphi_{d f}^{*}}\right)^{\sigma-1}-1\right] g(\varphi) d \varphi \\
& J\left(\varphi_{x f}^{*}\right)=\int_{\varphi_{x f}^{*}}^{\infty}\left[\left(\frac{\varphi}{\varphi_{x f}^{*}}\right)^{\sigma-1}-1\right] g(\varphi) d \varphi .
\end{aligned}
$$

\section{B Appendix: Determination of the Equilibrium}

\section{B.1 Derivation of Price Indices}

Using the equilibrium pricing rules, domestic cutoff productivity in China, foreign exporting productivity threshold, and the ex post productivity distributions from both countries, we obtain the price index in China:

$$
\begin{aligned}
P_{c}^{1-\sigma} & =\int_{0}^{\infty} p_{c}^{d}(\varphi)^{1-\sigma} M_{c}^{d} \mu_{c}^{d}(\varphi) d \varphi+\int_{0}^{\infty} p_{f}^{x}(\varphi)^{1-\sigma} M_{f}^{x} \mu_{f}^{x}(\varphi) d \varphi \\
& \left.\left.=\int_{\varphi_{d}^{*}}^{\infty} p_{c}^{d}(\varphi)^{1-\sigma} M_{c}^{d} \frac{g(\varphi)}{1-G\left(\varphi_{d}^{*}\right)}\right) d \varphi+\int_{\varphi_{x f}^{*}}^{\infty} p_{f}^{x}(\varphi)^{1-\sigma} M_{f}^{x} \frac{g(\varphi)}{1-G\left(\varphi_{x f}^{*}\right)}\right) d \varphi \\
& =\frac{M_{c}^{d}}{1-G\left(\varphi_{d}^{*}\right)} \int_{\varphi_{d}^{*}}^{\infty}\left(\frac{1}{\rho \varphi}\right)^{1-\sigma} g(\varphi) d \varphi+\frac{M_{f}^{x}}{1-G\left(\varphi_{x f}^{*}\right)} \int_{\varphi_{x f}^{*}}^{\infty}\left(\frac{\tau}{\rho \varphi}\right)^{1-\sigma} g(\varphi) d \varphi \\
& =M_{c}^{d}\left(\frac{w_{c}}{\rho}\right)^{1-\sigma} \frac{1}{1-G\left(\varphi_{d}^{*}\right)} \int_{\varphi_{d}^{*}}^{\infty} \varphi^{\sigma-1} g(\varphi) d \varphi+M_{f}^{x}\left(\frac{\tau w_{f}}{\rho}\right)^{1-\sigma} \frac{1}{1-G\left(\varphi_{x f}^{*}\right)} \int_{\varphi_{x f}^{*}}^{\infty} \varphi^{\sigma-1} g(\varphi) d \varphi \\
& =M_{c}^{d}\left(\frac{w_{c}}{\rho}\right)^{1-\sigma} \tilde{\varphi}_{c}^{d^{\sigma-1}}+M_{f}^{x}\left(\frac{\tau w_{f}}{\rho}\right)^{1-\sigma} \tilde{\varphi}_{f}^{x^{\sigma-1}} \\
& =M_{c}^{d} p_{c}^{d}\left(\tilde{\varphi}_{c}^{d}\right)^{1-\sigma}+M_{f}^{x} p_{f}^{x}\left(\tilde{\varphi}_{f}^{x}\right)^{1-\sigma}
\end{aligned}
$$

Analogously, using the equilibrium pricing rules, zero profit productivity cutoff in Foreign Country, pure and regular export productivity cutoff levels of Chinese firms, and the ex post productivity distributions 
from both countries, the price index in Foreign Country is obtained:

$$
\begin{aligned}
P_{f}^{1-\sigma} & =\int_{0}^{\infty} p_{f}^{d}(\varphi)^{1-\sigma} M_{f} \mu_{f}(\varphi) d \varphi+\int_{0}^{\infty} p_{c}^{x}(\varphi)^{1-\sigma} M_{c}^{x} \mu_{c}^{x}(\varphi) d \varphi+\int_{0}^{\infty} p_{c}^{s}(\varphi)^{1-\sigma} M_{c}^{s} \mu_{c}^{s}(\varphi) d \varphi \\
& =\int_{\varphi_{d f}^{*}}^{\infty} p_{f}^{d}(\varphi)^{1-\sigma} M_{f} \frac{g(\varphi)}{1-G\left(\varphi_{d f}^{*}\right)} d \varphi+\int_{\varphi_{x}^{*}}^{\infty} p_{c}^{x}(\varphi)^{1-\sigma} M_{c}^{f} \frac{g(\varphi)}{1-G\left(\varphi_{x}^{*}\right)} d \varphi \\
& +\int_{\varphi_{s}^{*}}^{\varphi_{d}^{*}} p_{c}^{s}(\varphi)^{1-\sigma} M_{c}^{s} \frac{g(\varphi)}{G\left(\varphi_{d}^{*}\right)-G\left(\varphi_{s}^{*}\right)} d \varphi \\
& =M_{f}\left(\frac{w_{f}}{\rho}\right)^{1-\sigma} \frac{1}{1-G\left(\varphi_{d f}^{*}\right)} \int_{\varphi_{d f}^{*}}^{\infty} \varphi^{\sigma-1} g(\varphi) d \varphi+M_{c}^{x}\left(\frac{\tau w_{c}}{\rho}\right)^{1-\sigma} \frac{1}{1-G\left(\varphi_{x}^{*}\right)} \int_{\varphi_{x}^{*}}^{\infty} \varphi^{\sigma-1} g(\varphi) d \varphi \\
& +M_{c}^{s}\left(\frac{\tau w_{c}}{\rho}\right)^{1-\sigma} \frac{1}{G\left(\varphi_{d}^{*}\right)-G\left(\varphi_{s}^{*}\right)} \int_{\varphi_{s}^{*}}^{\varphi_{d}^{*}} \varphi^{\sigma-1} g(\varphi) d \varphi \\
& =M_{f}\left(\frac{w_{f}}{\rho}\right)^{1-\sigma} \tilde{\varphi}_{f}^{d^{\sigma-1}}+M_{c}^{x}\left(\frac{\tau w_{c}}{\rho}\right)^{1-\sigma} \tilde{\varphi}_{c}^{x^{\sigma-1}}+M_{c}^{s}\left(\frac{\tau w_{c}}{\rho}\right)^{1-\sigma} \tilde{\varphi}_{c}^{s^{\sigma-1}} \\
& =M_{f}\left(\frac{w_{f}}{\rho \tilde{\varphi}_{f}^{d}}\right)^{1-\sigma}+M_{c}^{f}\left(\frac{\tau w_{c}}{\rho \tilde{\varphi}_{c}^{x}}\right)^{1-\sigma}+M_{c}^{s}\left(\frac{\tau w_{c}}{\rho \tilde{\varphi}_{c}^{s}}\right)^{1-\sigma} \\
& =M_{f} p_{f}^{d}\left(\tilde{\varphi}_{f}^{d}\right)^{1-\sigma}+M_{c}^{x} p_{c}^{x}\left(\tilde{\varphi}_{c}^{x}\right)^{1-\sigma}+M_{c}^{s} p_{c}^{s}\left(\tilde{\varphi}_{c}^{s}\right)^{1-\sigma}
\end{aligned}
$$

\section{B.2 Trade Balance Trade}

Balanced trade condition implies the representative agents in both countries each satisfying their respective budget constraint. It can be explicitly written as:

$$
\begin{aligned}
& \int r_{c}^{x} M_{c}^{x} \mu_{c}^{x}(\varphi) d \varphi+\int r_{c}^{s} M_{c}^{s} \mu_{c}^{s}(\varphi) d \varphi=\int r_{f}^{x} M_{f}^{x} \mu_{f}^{x}(\varphi) d \varphi \\
& \int_{0}^{\infty}\left(w_{c} \tau\right)^{1-\sigma} R_{f}\left(P_{f} \rho \varphi\right)^{\sigma-1} M_{c}^{x} \mu_{c}^{x}(\varphi) d \varphi+\int_{0}^{\infty}\left(w_{c} \tau\right)^{1-\sigma} R_{f}\left(P_{f} \rho \varphi\right)^{\sigma-1} M_{c}^{s} \mu_{c}^{s}(\varphi) d \varphi \\
& =\int_{0}^{\infty}\left(w_{f} \tau\right)^{1-\sigma} R_{c}\left(P_{c} \rho \varphi\right)^{\sigma-1} M_{f}^{x} \mu_{f}^{x}(\varphi) d \varphi \\
& \left(w_{c} \tau\right)^{1-\sigma} R_{f}\left(P_{f} \rho\right)^{\sigma-1} M_{c}^{x} \int_{\varphi_{x}^{*}}^{\infty} \varphi^{\sigma-1} \frac{g(\varphi)}{1-G\left(\varphi_{x}^{*}\right)} d \varphi \\
& +\left(w_{c} \tau\right)^{1-\sigma} R_{f}\left(P_{f} \rho\right)^{\sigma-1} M_{c}^{s} \int_{\varphi_{s}^{*}}^{\varphi_{d}^{*}} \varphi^{\sigma-1} \frac{g(\varphi)}{G\left(\varphi_{d}^{*}\right)-G\left(\varphi_{s}^{*}\right)} d \varphi \\
& =\left(w_{f} \tau\right)^{1-\sigma} R_{c}\left(P_{c} \rho\right)^{\sigma-1} M_{f}^{x} \int_{\varphi_{x f}^{*}}^{\infty} \varphi^{\sigma-1} \frac{g(\varphi)}{1-G\left(\varphi_{x f}^{*}\right)} d \varphi \\
& \left(w_{c} \tau\right)^{1-\sigma} R_{f}\left(P_{f} \rho\right)^{\sigma-1} M_{c}^{x} \frac{1}{1-G\left(\varphi_{x}^{*}\right)} \int_{\varphi_{x}^{*}}^{\infty} \varphi^{\sigma-1} g(\varphi) d \varphi \\
& +\left(w_{c} \tau\right)^{1-\sigma} R_{f}\left(P_{f} \rho\right)^{\sigma-1} M_{c}^{s} \frac{1}{G\left(\varphi_{d}^{*}\right)-G\left(\varphi_{s}^{*}\right)} \int_{\varphi_{s}^{*}}^{\varphi_{d}^{*}} \varphi^{\sigma-1} g(\varphi) d \varphi \\
& =\left(w_{f} \tau\right)^{1-\sigma} R_{c}\left(P_{c} \rho\right)^{\sigma-1} M_{f}^{x} \frac{1}{1-G\left(\varphi_{x f}^{*}\right)} \int_{\varphi_{x f}^{*}}^{\infty} \varphi^{\sigma-1} g(\varphi) d \varphi \\
& \left(w_{c} \tau\right)^{1-\sigma} R_{f}\left(P_{f} \rho\right)^{\sigma-1} M_{c}^{x} \tilde{\varphi}_{c}^{x^{\sigma-1}}+\left(w_{c} \tau\right)^{1-\sigma} R_{f}\left(P_{f} \rho\right)^{\sigma-1} M_{c}^{s} \tilde{\varphi}_{c}^{s^{\sigma-1}} \\
& =\left(w_{f} \tau\right)^{1-\sigma} R_{c}\left(P_{c} \rho\right)^{\sigma-1} M_{f}^{x} \tilde{\varphi}_{f}^{x^{\sigma-1}} \\
& \left(w_{c} \tau\right)^{1-\sigma} R_{f}\left(P_{f} \rho \tilde{\varphi}_{c}^{x}\right)^{\sigma-1} M_{c}^{x}+\left(w_{c} \tau\right)^{1-\sigma} R_{f}\left(P_{f} \rho \tilde{\varphi}_{c}^{s}\right)^{\sigma-1} M_{c}^{s}
\end{aligned}
$$




$$
\begin{gathered}
=\left(w_{f} \tau\right)^{1-\sigma} R_{c}\left(P_{c} \rho \tilde{\varphi}_{f}^{x}\right)^{\sigma-1} M_{f}^{x} \\
r_{c}^{f}\left(\tilde{\varphi}_{c}^{x}\right) M_{c}^{x}+r_{c}^{s}\left(\tilde{\varphi}_{c}^{s}\right) M_{c}^{s}=r_{f}^{x}\left(\tilde{\varphi}_{f}^{x}\right) M_{f}^{x}
\end{gathered}
$$

\section{B.3 Existence and Uniqueness of the Equilibrium Cutoff Level}

With asymmetric countries, the steady-state industry equilibrium can be referenced by a vector of variables $\left\{\varphi_{s}^{*}, \varphi_{d}^{*}, \varphi_{x}^{*}, \varphi_{d f}^{*}, \varphi_{x f}^{*}, R_{c}, R_{f}, P_{c}, P_{f}\right\}$, in terms of which all other endogenous variable can be written. First, we repeat the free entry conditions

$$
\begin{aligned}
& f_{e}=\frac{f}{\delta} J\left(\varphi_{s}^{*}\right)+\frac{f+f_{d}}{\delta} J\left(\varphi_{d}^{*}\right)+\frac{f_{x}}{\delta} J\left(\varphi_{x}^{*}\right), \\
& f_{e}=\frac{f+f_{d}}{\delta} J\left(\varphi_{d f}^{*}\right)+\frac{f_{x}}{\delta} J\left(\varphi_{x f}^{*}\right),
\end{aligned}
$$

where $\varphi_{s}^{*}=\varphi_{d}^{*} \tau\left(\frac{f}{f+f_{d}}\right)^{\frac{1}{\sigma-1}}, \varphi_{x}^{*}=\varphi_{d}^{*} \tau\left(\frac{f_{x}}{f+f_{d}}\right)^{\frac{1}{\sigma-1}}$ are implicit defined as a function of $\varphi_{d}^{*}$; and $\varphi_{x f}^{*}=$ $\varphi_{d f}^{*} \tau\left(\frac{f_{x}}{f+f_{d}}\right)^{\frac{1}{\sigma-1}}$ is defined a function of $\varphi_{d f}^{*}$.

\section{Proof $J(\varphi)$ is decreasing function on $(0,+\infty)$}

For pure exporters, we have

$$
\begin{aligned}
J\left(\varphi_{s}^{*}\right) & =\int_{\varphi_{s}^{*}}^{\varphi_{d}^{*}}\left[\left(\frac{\varphi}{\varphi_{s}^{*}}\right)^{\sigma-1}-1\right] g(\varphi) d \varphi \\
& =\int_{\varphi_{s}^{*}}^{\varphi_{d}^{*}}\left(\frac{\varphi}{\varphi_{s}^{*}}\right)^{\sigma-1} g(\varphi) d \varphi-\int_{\varphi_{s}^{*}}^{\varphi_{d}^{*}} g(\varphi) d \varphi \\
& =\varphi_{s}^{* 1-\sigma} \int_{\varphi_{s}^{*}}^{\varphi_{d}^{*}} \varphi^{\sigma-1} g(\varphi) d \varphi-\left[G\left(\varphi_{d}^{*}\right)-G\left(\varphi_{s}^{*}\right)\right. \\
& =\varphi_{s}^{* 1-\sigma}\left(\tilde{\varphi}_{c}^{s}\right)^{\sigma-1}\left[G\left(\varphi_{d}^{*}\right)-G\left(\varphi_{s}^{*}\right)\right]-\left[G\left(\varphi_{d}^{*}\right)-G\left(\varphi_{s}^{*}\right)\right] \\
& =\left[G\left(\varphi_{d}^{*}\right)-G\left(\varphi_{s}^{*}\right)\right]\left[\left(\frac{\tilde{\varphi}_{c}^{s}}{\varphi_{s}^{*}}\right)^{\sigma-1}-1\right] \\
& =\left[G\left(\varphi_{d}^{*}\right)-G\left(\varphi_{s}^{*}\right)\right] k\left(\varphi_{s}^{*}\right)
\end{aligned}
$$

Recall that $k\left(\varphi_{s}^{*}\right)$ is defined as

$$
k\left(\varphi_{s}^{*}\right)=\left(\varphi_{s}^{*}\right)^{1-\sigma} \frac{1}{G\left(\varphi_{d}^{*}\right)-G\left(\varphi_{s}^{*}\right)} \int_{\varphi_{s}^{*}}^{\varphi_{d}^{*}} \varphi^{\sigma-1} g(\varphi) d \varphi-1 .
$$

Differentiating $\mathrm{B} .2$ with respect to $\varphi_{s}^{*}$ yields:

$$
\begin{aligned}
k^{\prime}\left(\varphi_{s}^{*}\right) & =\frac{g\left(\varphi_{s}^{*}\right)}{\left[G\left(\varphi_{d}^{*}\right)-G\left(\varphi_{s}^{*}\right)\right]^{2}}\left(\varphi_{s}^{*}\right)^{1-\sigma} \int_{\varphi_{s}^{*}}^{\varphi_{d}^{*}} \varphi^{\sigma-1} g(\varphi) d \varphi+\frac{\left(\varphi_{s}^{*}\right)^{1-\sigma}}{G\left(\varphi_{d}^{*}\right)-G\left(\varphi_{s}^{*}\right)}\left[-\left(\varphi_{s}^{*}\right)^{\sigma-1} g\left(\varphi_{s}^{*}\right)\right] \\
& +(1-\sigma)\left(\varphi_{s}^{*}\right)^{-1}\left[\frac{\tilde{\varphi}_{c}^{s}\left(\varphi_{s}^{*}\right)}{\varphi_{s}^{*}}\right]^{\sigma-1} \\
& =\frac{g\left(\varphi_{s}^{*}\right)\left(\varphi_{s}^{*}\right)^{1-\sigma}}{G\left(\varphi_{d}^{*}\right)-G\left(\varphi_{s}^{*}\right)} \underbrace{\frac{1}{G\left(\varphi_{d}^{*}\right)-G\left(\varphi_{s}^{*}\right)} \int_{\varphi_{s}^{*}}^{\varphi_{d}^{*}} \varphi^{\sigma-1} g(\varphi) d \varphi}_{\left(\tilde{\varphi}_{c}^{s}\right)^{\sigma-1}}-\frac{g\left(\varphi_{s}^{*}\right)}{G\left(\varphi_{d}^{*}\right)-G\left(\varphi_{s}^{*}\right)}+\frac{\sigma-1}{\varphi_{s}^{*}}\left[\frac{\tilde{\varphi}_{c}^{s}\left(\varphi_{s}^{*}\right)}{\varphi_{s}^{*}}\right]^{\sigma-1}
\end{aligned}
$$




$$
\begin{aligned}
& =\frac{g\left(\varphi_{s}^{*}\right)}{G\left(\varphi_{d}^{*}\right)-G\left(\varphi_{s}^{*}\right)}\left(\frac{\tilde{\varphi}_{c}^{s}\left(\varphi_{s}^{*}\right)}{\varphi_{s}^{*}}\right)^{\sigma-1}-\frac{g\left(\varphi_{s}^{*}\right)}{G\left(\varphi_{d}^{*}\right)-G\left(\varphi_{s}^{*}\right)}-\frac{\sigma-1}{\varphi_{s}^{*}}\left(\frac{\tilde{\varphi}_{c}^{s}\left(\varphi_{s}^{*}\right)}{\varphi_{s}^{*}}\right)^{\sigma-1} \\
& =\frac{g\left(\varphi_{s}^{*}\right)}{G\left(\varphi_{d}^{*}\right)-G\left(\varphi_{s}^{*}\right)}\left[\left(\frac{\tilde{\varphi}_{c}^{s}\left(\varphi_{s}^{*}\right)}{\varphi_{s}^{*}}\right)^{\sigma-1}-1\right]-\frac{\sigma-1}{\varphi_{s}^{*}}\left(k\left(\varphi_{s}^{*}\right)+1\right) \\
& =\frac{g\left(\varphi_{s}^{*}\right)}{G\left(\varphi_{d}^{*}\right)-G\left(\varphi_{s}^{*}\right)} k\left(\varphi_{s}^{*}\right)-\frac{\sigma-1}{\varphi_{s}^{*}}\left(k\left(\varphi_{s}^{*}\right)+1\right)
\end{aligned}
$$

We have defined $J\left(\varphi_{s}^{*}\right)=\left[G\left(\varphi_{d}^{*}\right)-G\left(\varphi_{s}^{*}\right)\right] k\left(\varphi_{s}^{*}\right)$, then its derivative and elasticity is given by:

$$
\begin{aligned}
J^{\prime}\left(\varphi_{s}^{*}\right) & =-g^{\prime}\left(\varphi_{s}^{*}\right) k\left(\varphi_{s}^{*}\right)+\left(G\left(\varphi_{d}^{*}\right)-G\left(\varphi_{s}^{*}\right)\right) k^{\prime}\left(\varphi_{s}^{*}\right) \\
& =-g^{\prime}\left(\varphi_{s}^{*}\right) k\left(\varphi_{s}^{*}\right)+\left(G\left(\varphi_{d}^{*}\right)-G\left(\varphi_{s}^{*}\right)\right)\left[\frac{g\left(\varphi_{s}^{*}\right)}{G\left(\varphi_{d}^{*}\right)-G\left(\varphi_{s}^{*}\right)} k\left(\varphi_{s}^{*}\right)-\frac{\sigma-1}{\varphi_{s}^{*}}\left(k\left(\varphi_{s}^{*}\right)+1\right)\right] \\
& =-\frac{1}{\varphi_{s}^{*}}(\sigma-1)\left(G\left(\varphi_{d}^{*}\right)-G\left(\varphi_{s}^{*}\right)\right)\left(k\left(\varphi_{s}^{*}\right)+1\right)<0 . \\
\frac{J^{\prime}\left(\varphi_{s}^{*}\right) \varphi_{s}^{*}}{J\left(\varphi_{s}^{*}\right)} & =\frac{\frac{1}{\varphi_{s}^{*}} \varphi_{s}^{*}(\sigma-1)\left(G\left(\varphi_{d}^{*}\right)-G\left(\varphi_{s}^{*}\right)\right)\left(k\left(\varphi_{s}^{*}\right)+1\right)}{\left[G\left(\varphi_{d}^{*}\right)-G\left(\varphi_{s}^{*}\right)\right] k\left(\varphi_{s}^{*}\right)} \\
& =-(\sigma-1)\left(1+\frac{1}{k\left(\varphi_{s}^{*}\right)}\right)<-(\sigma-1) .
\end{aligned}
$$

For the rest types of firms, we proceed our proof as follows 10 recall that $k(\varphi)=\left(\frac{\tilde{\varphi}(\varphi)}{\varphi}\right)^{\sigma-1}-1$ where the aggregate productivities of all other types firms are defined as:

$$
\tilde{\varphi}(\varphi)^{\sigma-1}=\frac{1}{1-G(\varphi)} \int_{\varphi}^{\infty} \xi^{\sigma-1} g(\xi) d \xi
$$

Differentiating (B.5) with respect to $\varphi$ yields:

$$
\frac{\partial \tilde{\varphi}(\varphi)^{\sigma-1}}{\partial \varphi}=\frac{g(\varphi)}{1-G(\varphi)}\left[\tilde{\varphi}(\varphi)^{\sigma-1}-\varphi^{\sigma-1}\right]
$$

Therefore

$$
\begin{aligned}
k^{\prime}(\varphi) & =\frac{g(\varphi)}{1-G(\varphi)}\left[\left(\frac{\tilde{\varphi}(\varphi)}{\varphi}\right)^{\sigma-1}-1\right]-\left(\frac{\tilde{\varphi}(\varphi)}{\varphi}\right)^{\sigma-1} \frac{\sigma-1}{\varphi} \\
& =\frac{k(\varphi) g(\varphi)}{1-G(\varphi)}-\frac{(\sigma-1)[k(\varphi)+1]}{\varphi} \\
& =\frac{k(\varphi) g(\varphi) \varphi-(\sigma-1)[k(\varphi)+1](1-G(\varphi))}{(1-G(\varphi)) \varphi}
\end{aligned}
$$

We have defined $J(\varphi)=[1-G(\varphi)] k(\varphi)$, then its derivative and elasticity are given by:

$$
\begin{aligned}
& J^{\prime}(\varphi)=-\frac{1}{\varphi}(\sigma-1)[k(\varphi)+1](1-G(\varphi))<0, \\
& \frac{J^{\prime}(\varphi) \varphi}{J(\varphi)}=-(\sigma-1)\left(1+\frac{1}{k(\varphi)}\right)<-(\sigma-1) .
\end{aligned}
$$

\footnotetext{
${ }^{10}$ this proof is from Melitz (2003)
} 
Therefore, we have proved $J(\varphi)$ is non-negative and its elasticity with respect to $\varphi$ is negative and bounded away from zero, $J(\varphi)$ must be decreasing to zero as $\varphi$ goes to infinity. Furthermore, $\lim _{\varphi \rightarrow 0} J(\varphi)=\infty$ since $\lim _{\varphi \rightarrow 0} k(\varphi)=\infty$. Thus, $J(\varphi)=[1-G(\varphi)] k(\varphi)$ decreases from infinity to zero on $(0, \infty) ; \frac{\partial \varphi_{s}^{*}}{\partial \varphi_{d}^{*}}, \frac{\partial \varphi_{x}^{*}}{\partial \varphi_{d}^{*}}$ and $\frac{\partial \varphi_{x f}^{*}}{\partial \varphi_{d f}^{*}}$ are all positive. Consequently, the left hand side of (21) and 222 must also monotonically decrease from infinity to zero on $(0, \infty)$. The right-hand side of these two equations are constant. Consequently, 21) identifies a unique cutoff level $\varphi_{d}^{*}$ in China and 22) determines the industry productivity cutoff $\varphi_{d f}^{*}$ in Foreign Country. Having determined these two cutoffs, all other productivity cutoffs $\varphi_{s}^{*}, \varphi_{x}^{*}$ and $\varphi_{x f}^{*}$ follows immediately from the relationship between the productivity offs from (18)- (20). These unique productivity cutoffs, in turn, determine the average productivity levels according to formulas (11) - (13). The ex ante successful entry in both countries, domestic and regular export probabilities are also fixed.

Aggregate revenue is exogenously determined and must equal the labor supply multiply wage, $R_{i}=w_{i} L$ in both countries. The price index $P_{c}(23)$ has two components: the prices of a variety with weighted average productivity in China and Foreign Country, $p_{c}^{d}\left(\tilde{\varphi}_{c}^{d}\right)$ and $p_{f}^{x}\left(\tilde{\varphi}_{f}^{x}\right)$; the mass of foreign firms that export to China $M_{f}^{x}=p_{f}^{x} M_{f}$, and the mass of Chinese regular firms, $M_{c}^{d}$. The prices $p_{c}^{d}\left(\tilde{\varphi}_{c}^{d}\right)$ and $p_{f}^{x}\left(\tilde{\varphi}_{f}^{x}\right)$ depend solely on weighted average productivities in each market, $\tilde{\varphi}_{c}^{d}$ and $\tilde{\varphi}_{f}^{x}$, which in turn depend solely by two productivity cutoffs, $\varphi_{d}^{*}$ and $\varphi_{x f}^{*}$, that were determined in (12) and (17). The probability of foreign firms export to China, $p_{f}^{x}=\left[1-G\left(\varphi_{x f}^{*}\right)\right] /\left[1-G\left(\varphi_{d f}^{*}\right)\right]$, also follows from the two productivity cutoffs, $\varphi_{d f}^{*}$ and $\varphi_{x f}^{*}$. Similarly, the price index $P_{f} 24$ in Foreign Country consists of three terms: the prices of a variety with weighted average productivity from foreign producers $p_{f}^{d}\left(\tilde{\varphi}_{f}^{d}\right)$, Chinese pure exporters $p_{c}^{s}\left(\tilde{\varphi}_{c}^{s}\right)$ and regular ones $p_{c}^{x}\left(\tilde{\varphi}_{c}^{x}\right)$; the mass of foreign firms $M_{f}$, the mass of Chinese pure exporters $M_{c}^{s}$ and regular exporters $M_{c}^{x}$. The prices $p_{f}^{d}\left(\tilde{\varphi}_{f}^{d}\right), p_{c}^{s}\left(\tilde{\varphi}_{c}^{s}\right)$ and $p_{c}^{x}\left(\tilde{\varphi}_{c}^{x}\right)$ are solely rely on three productivity cutoffs, $\varphi_{d f}^{*}, \varphi_{s}^{*}$ and $\varphi_{x}^{*}$ that were determined above. The probability of being Chinese pure exporters, $p_{c}^{s}=\left[G\left(\varphi_{d}^{*}\right)-G\left(\varphi_{s}^{*}\right)\right] /\left[1-G\left(\varphi_{s}^{*}\right)\right]$, and the probability of regular export from China to Foreign Country $p_{c}^{x}=\left[1-G\left(\varphi_{x}^{*}\right)\right] /\left[1-G\left(\varphi_{d}^{*}\right)\right]$, also follows from the productivity cutoffs, $\varphi_{s}^{*}, \varphi_{d}^{*}$ and $\varphi_{x}$. Finally, the mass of firms in both regions equals the ratio of aggregate revenue to average revenue, as shown in (25) and (26). Aggregate revenue was solved above, while average revenue depends solely on the already-determined productive cutoffs. This completes the characterization of the equilibrium.

\section{B.4 Welfare}

Welfare in Chinese market can also be written as a function of the cutoff productivity of $\varphi_{d}^{*}$ :

$$
\mathbb{W}_{c}=\frac{w_{c}}{R_{c}}=\rho\left(\frac{L}{\sigma w_{c}\left(f+f_{d}\right)}\right)^{\frac{1}{\sigma-1}} \varphi_{d}^{*}
$$


Similarly, welfare per worker in Foreign country is determined by the domestic zero cutoff profit condition:

$$
\mathbb{W}_{f}=\frac{w_{f}}{R_{f}}=\rho\left(\frac{L}{\sigma w_{f}\left(f+f_{d}\right)}\right)^{\frac{1}{\sigma-1}} \varphi_{d f}^{*}
$$

Since $\varphi_{d f}^{*}>\varphi_{d}^{*}$, welfare in foreign country must be higher than in China: $\mathbb{W}_{f}>\mathbb{W}_{c}$.

\section{Appendix: The Impact of Trade Liberalization}

These comparative statics are all derived from the equilibrium condition for the cutoff levels from 21. and (22); and the implicit definition of $\varphi_{x}^{*}$ and $\varphi_{s}^{*}$ as a function of $\varphi_{d}^{*}$ from (17) and (18) in China; $\varphi_{x f}^{*}$ as a function of $\varphi_{d f}^{*}$ from 19 in Foreign Country.

\section{C.1 Decrease in Fixed Export Trade Costs}

Changes in the cutoff levels:

Differentiating $f_{x}$ with respect to $\varphi_{x}^{*}=\tau \varphi_{d}^{*}\left(\frac{f_{x}}{f+f_{d}}\right)^{\frac{1}{\sigma-1}}$ yields $\frac{\partial \varphi_{x}^{*}}{\partial f_{x}}=\frac{1}{\sigma-1} \frac{\varphi_{x}^{*}}{f_{x}}+\frac{\varphi_{x}^{*}}{\varphi_{d}^{*}} \frac{\partial \varphi_{d}^{*}}{\partial f_{x}}$.

Differentiating $f_{x}$ with respect to $\varphi_{s}^{*}=\tau \varphi_{d}^{*}\left(\frac{f}{f+f_{d}}\right)^{\frac{1}{\sigma-1}}$ yields $\frac{\partial \varphi_{s}^{*}}{\partial f_{x}}=\frac{\varphi_{s}^{*}}{\varphi_{d}^{*}} \frac{\partial \varphi_{d}^{*}}{\partial f_{x}}$.

Differentiating $f_{x}$ with respect to $\varphi_{x f}^{*}=\tau \varphi_{d f}^{*}\left(\frac{f_{x}}{f+f_{d}}\right)^{\frac{1}{\sigma-1}}$ yields $\frac{\partial \varphi_{x f}^{*}}{\partial f_{x}}=\frac{1}{\sigma-1} \frac{\varphi_{x f}^{*}}{f_{x}}+\frac{\varphi_{x f}^{*}}{\varphi_{d f}^{*}} \frac{\partial \varphi_{d f}^{*}}{\partial f_{x}}$.

Differentiating free entry conditions of 21 and 22 in both countries with respect to $f_{x}$, we obtain

$$
\begin{aligned}
& f J^{\prime}\left(\varphi_{s}^{*}\right) \frac{\partial \varphi_{s}^{*}}{\partial f_{x}}+\left(f+f_{d}\right) J^{\prime}\left(\varphi_{d}^{*}\right) \frac{\partial \varphi_{d}^{*}}{\partial f_{x}}+J\left(\varphi_{x}^{*}\right)+f_{x} J^{\prime}\left(\varphi_{x}^{*}\right) \frac{\partial \varphi_{x}^{*}}{\partial f_{x}}=0 \\
& \left(f+f_{d}\right) J^{\prime}\left(\varphi_{d f}^{*}\right) \frac{\partial \varphi_{d f}^{*}}{\partial f_{x}}+J\left(\varphi_{x f}^{*}\right) f_{x} J^{\prime}\left(\varphi_{x f}^{*}\right) \frac{\partial \varphi_{x f}^{*}}{\partial f_{x}}=0
\end{aligned}
$$

Combing the above conditions yields:

$$
\begin{aligned}
\frac{\partial \varphi_{d}^{*}}{\partial f_{x}} & =\frac{1-G\left(\varphi_{x}^{*}\right)}{f J^{\prime}\left(\varphi_{s}^{*}\right) \frac{\varphi_{s}^{*}}{\varphi_{d}^{*}}+\left(f+f_{d}\right) J^{\prime}\left(\varphi_{d}^{*}\right)+f_{x} J^{\prime}\left(\varphi_{x}^{*}\right) \frac{\varphi_{x}^{*}}{\varphi_{d}^{*}}}<0, \\
\frac{\partial \varphi_{d f}^{*}}{\partial f_{x}} & =\frac{1-G\left(\varphi_{x f}^{*}\right)}{\left(f+f_{d}\right) J^{\prime}\left(\varphi_{d f}^{*}\right)+f_{x} J^{\prime}\left(\varphi_{x f}^{*}\right) \frac{\varphi_{x f}^{*}}{\varphi_{d f}^{*}}}<0,
\end{aligned}
$$

since $J^{\prime}(\varphi)<0 \forall \varphi$, and

$$
\begin{aligned}
& \frac{\partial \varphi_{x}^{*}}{\partial f_{x}}=-\frac{1}{f_{x} J^{\prime}\left(\varphi_{x}^{*}\right)}\left[\left(f+f_{d}\right) J^{\prime}\left(\varphi_{d}^{*}\right) \frac{\partial \varphi_{d}^{*}}{\partial f_{x}}+f J^{\prime}\left(\varphi_{s}^{*}\right) \frac{\varphi_{s}^{*}}{\varphi_{x}^{*}} \frac{\partial \varphi_{d}^{*}}{\partial f_{x}}+J\left(\varphi_{x}^{*}\right)\right]>0, \\
& \frac{\partial \varphi_{s}^{*}}{\partial f_{x}}=\frac{\varphi_{s}^{*}}{\varphi_{d}^{*}} \frac{\partial \varphi_{d}^{*}}{\partial f_{x}}<0, \\
& \frac{\partial \varphi_{x f}^{*}}{\partial f_{x}}=-\frac{1}{f_{x f} J^{\prime}\left(\varphi_{x f}^{*}\right)}\left[J\left(\varphi_{x f}^{*}\right)+\left(f+f_{d}\right) J^{\prime}\left(\varphi_{d f}^{*}\right) \frac{\partial \varphi_{d f}^{*}}{\partial f_{x}}\right]>0 .
\end{aligned}
$$


Welfare: Recall from (B.8) and (B.9) that welfare must therefore rise with the decrease in $f_{x}$ since all of these changes induce an increase in the domestic cutoff productivity levels $\varphi_{d}^{*}$ and $\varphi_{d f}^{*}$.

The decrease in fixed export cost $f_{x}$ induces an increase in the cutoff productivity level of pure exporters. Recall that $r_{c}^{s}(\varphi)=\left(\varphi / \varphi_{s}^{*}\right)^{\sigma-1} \sigma w_{c} f\left(\forall \varphi_{s}^{*} \leq \varphi<\varphi_{d}^{*}\right)$. $r_{c}^{s}(\varphi)$ therefore decreases with falling export barriers since this change induces an increase in the cutoff productivity level. Thus $r_{c}^{s \prime}(\varphi)<r_{c}^{s}(\varphi)$ whenever $f_{x}{ }^{\prime}<f_{x}$ since $\varphi_{s}^{* \prime}>\varphi_{s}^{*}$. In other words, the decline in export market access costs drives the least efficient pure exporters out of the market, and reduces revenue and profits of all existing pure exporters.

A decrease in $f_{x}$ induces an increase in the domestic cutoff levels in both countries. Take China as an example, recall that $r_{c}^{d}(\varphi)=\left(\varphi / \varphi_{d}^{* \sigma-1}\right) \sigma w_{c}\left(f+f_{d}\right) \forall \varphi \geq \varphi_{d}^{*}$. Thus, $r_{c}^{d^{\prime}}(\varphi)<r_{c}^{d}(\varphi), \forall \varphi \geq \varphi_{d}^{* \prime}$ since $\varphi_{d}^{* \prime}>\varphi_{d}^{*}$. All existing domestic producers in the new equilibrium with $f_{x}{ }^{\prime}$ fixed export cost lose a fraction of revenue from the domestic market. In particular, regular producers in China with productivity levels between $\varphi_{d}^{*}$ and $\varphi_{d}^{* \prime}$ switch to pursue processing trade, while the foreign firms with productivity $\varphi \in\left[\varphi_{d f}^{*}, \varphi_{d f}^{*}{ }^{\prime}\right)$ exit.

For firms that already exported $\left(\varphi \geq \varphi_{x}^{*}\right)$ prior to the change in $f_{x}$, the direction of change in combined domestic and export sales $r_{c}^{d}(\varphi)+r_{c}^{x}(\varphi)=\left(1+\tau^{1-\sigma}\right) r_{c}^{d}(\varphi)$ decreases in the same proportion as its domestic sales when $f_{x}$ decreases since $1+\tau^{\sigma-1}$ remains constant.

Trade liberalization in $f_{x}$ reduces the regular export cutoffs in both regions, and hence generates a new category of firms with intermediate productivity levels $\left(\varphi_{x}^{* \prime} \leq \varphi<\varphi_{x}^{*}\right)$ that enters the export market as a consequence of the decrease in $f_{x}$. The new export sales generate an increase in revenue for all these firms since $r_{c}^{d}(\varphi)<r_{d}^{c}(\varphi)+r_{c}^{x}(\varphi)=\left(1+\tau^{\sigma-1}\right) r_{c}^{d}(\varphi)$.

\section{C.2 Decrease in Variable Trade Costs}

Changes in the cutoff levels:

Differentiating $\tau$ with respect to $\varphi_{x}^{*}=\tau \varphi_{d}^{*}\left(\frac{f_{x}}{f+f_{d}}\right)^{\frac{1}{\sigma-1}}$ yields $\frac{\partial \varphi_{x}^{*}}{\partial \tau}=\frac{\varphi_{x}^{*}}{\tau}+\frac{\varphi_{x}^{*}}{\varphi_{d}^{*}} \frac{\partial \varphi_{d}^{*}}{\partial \tau}$.

Differentiating $\tau$ with respect to $\varphi_{s}^{*}=\tau \varphi_{d}^{*}\left(\frac{f}{f+f_{d}}\right)^{\frac{1}{\sigma-1}}$ yields $\frac{\partial \varphi_{s}^{*}}{\partial \tau}=\frac{\varphi_{s}^{*}}{\tau}+\frac{\varphi_{s}^{*}}{\varphi_{d}^{*}} \frac{\partial \varphi_{d}^{*}}{\partial \tau}$.

Differentiating $\tau$ with respect to $\varphi_{x f}^{*}=\tau \varphi_{d f}^{*}\left(\frac{f_{x}}{f+f_{d}}\right)^{\frac{1}{\sigma-1}}$ yields $\frac{\partial \varphi_{x f}^{*}}{\partial \tau}=\frac{\varphi_{x f}^{*}}{\tau}+\frac{\varphi_{x f}^{*}}{\varphi_{d f}^{*}} \frac{\partial \varphi_{d f}^{*}}{\partial \tau}$.

Differentiating (21) and 22 in both countries with respect to $\tau$ yields:

$$
\begin{aligned}
& f J^{\prime}\left(\varphi_{s}^{*}\right) \frac{\partial \varphi_{s}^{*}}{\partial \tau}+\left(f+f_{d}\right) J^{\prime}\left(\varphi_{d}^{*}\right) \frac{\partial \varphi_{d}^{*}}{\partial \tau}+f_{x} J^{\prime}\left(\varphi_{x}^{*}\right) \frac{\partial \varphi_{x}^{*}}{\partial \tau}=0 \\
& \left(f+f_{d}\right) J^{\prime}\left(\varphi_{d f}^{*}\right) \frac{\partial \varphi_{d f}^{*}}{\partial \tau}+f_{x} J^{\prime}\left(\varphi_{x f}^{*}\right) \frac{\partial \varphi_{x f}^{*}}{\partial \tau}=0
\end{aligned}
$$


Combining the above conditions together yields:

$$
\begin{aligned}
& \frac{\partial \varphi_{d}^{*}}{\partial \tau}=-\frac{\varphi_{d}^{*}}{\tau} \frac{f J^{\prime}\left(\varphi_{s}^{*}\right) \varphi_{s}^{*}+f_{x} J^{\prime}\left(\varphi_{x}^{*}\right) \varphi_{x}^{*}}{f J^{\prime}\left(\varphi_{s}^{*}\right) \varphi_{s}^{*}+\left(f+f_{d}\right) J^{\prime}\left(\varphi_{d}^{*}\right) \varphi_{d}^{*}+f_{x} J^{\prime}\left(\varphi_{x}^{*}\right) \varphi_{x}^{*}}<0, \\
& \frac{\partial \varphi_{d f}^{*}}{\partial \tau}=-\frac{\varphi_{d f}^{*}}{\tau} \frac{f_{x} J^{\prime}\left(\varphi_{x f}^{*}\right) \varphi_{x f}^{*}}{\left(f+f_{d}\right) J^{\prime}\left(\varphi_{d f}^{*}\right) \varphi_{d f}^{*}+f_{x} J^{\prime}\left(\varphi_{x f}^{*}\right) \varphi_{x f}^{*}}<0,
\end{aligned}
$$

since $J^{\prime}(\varphi)<0 \forall \varphi$, and

$$
\begin{aligned}
& \frac{\partial \varphi_{s}^{*}}{\partial \tau}=-\frac{\left(f+f_{d}\right) J^{\prime}\left(\varphi_{d}^{*}\right)}{f J^{\prime}\left(\varphi_{s}^{*}\right)+f_{x} J^{\prime}\left(\varphi_{x}^{*}\right) \frac{\varphi_{x}^{*}}{\varphi_{s}^{*}}} \frac{\partial \varphi_{d}^{*}}{\partial \tau}>0, \\
& \frac{\partial \varphi_{x}^{*}}{\partial \tau}=-\frac{\left(f+f_{d}\right) J^{\prime}\left(\varphi_{d}^{*}\right)}{f J^{\prime}\left(\varphi_{s}^{*}\right) \frac{\varphi_{s}^{*}}{\varphi_{x}^{*}}+f_{x} J^{\prime}\left(\varphi_{x}^{*}\right)} \frac{\partial \varphi_{d}^{*}}{\partial \tau}>0, \\
& \frac{\partial \varphi_{x f}^{*}}{\partial \tau}=-\frac{\left(f+f_{d}\right) J^{\prime}\left(\varphi_{d f}^{*}\right)}{f_{x} J\left(\varphi_{x f}^{*}\right)} \frac{\partial \varphi_{d f}^{*}}{\partial \tau}>0 .
\end{aligned}
$$

Welfare: Recall from $(\overline{B .8})$ and $(\overline{B .9})$ that welfare must therefore rise with decrease in $\tau$ since all of these changes induce an increase in the cutoff productivity levels $\varphi_{d}^{*}$ and $\varphi_{d f}^{*}$.

As stated previously, we have $r_{c}^{s}(\varphi)=\left(\varphi / \varphi_{s}^{*}\right)^{\sigma-1} \sigma w_{c} f\left(\forall \varphi_{s}^{*} \leq \varphi<\varphi_{d}^{*}\right) \cdot r_{c}^{s}(\varphi)$ therefore increases with decreases in $\tau$ since this change induces a decrease in the cutoff productivity of pure exporters $\left(\varphi_{s}^{*} \downarrow\right)$. Thus $r_{c}^{s^{\prime}}(\varphi)>r_{c}^{s}(\varphi) \forall \varphi_{s}^{*} \leq \varphi<\varphi_{d}^{*}$ whenever $\tau^{\prime}<\tau$ (since $\varphi_{s}^{* \prime}<\varphi_{s}^{*}$ ).

With respect to Chinese domestic producers, recall that $r_{c}^{d}(\varphi)=\left(\varphi / \varphi_{d}^{*}\right)^{\sigma-1} \sigma w_{c}\left(f+f_{d}\right)\left(\forall \varphi \geq \varphi_{d}^{*}\right)$. A decrease in $\tau$ induce an increase in the domestic cutoff productivity level $\left(\varphi_{d}^{*} \uparrow\right)$ and $r_{c}^{d}(\varphi)$ therefore decreases. Foreign Country also behaves the similar pattern that freer trade improves the industry productivity threshold and reduces the revenue and profits of all existing domestic firms. However, in contrast to Foreign Country, a set of Chinese firms with productivity $\varphi \in\left[\varphi_{d}^{*}, \varphi_{d}^{* \prime}\right)$ which would have otherwise been forced to exit switching to processing trade in face of decreasing $\tau$.

Take China as an example, the direction of the change in combined domestic and export sales of Chinese regular exporters, $r_{c}^{d}(\varphi)+r_{c}^{x}(\varphi)=\left(1+\tau^{1-\sigma}\right) r_{c}^{d}(\varphi)$ 11, will depend on the direction of the change in $\left(1+\tau^{1-\sigma}\right) /\left(\varphi_{d}^{*}\right)^{\sigma-1}$. It is now shown that these combined sales increase when $\tau$ decreases as $\left(1+\tau^{1-\sigma}\right) /\left(\varphi_{d}^{*}\right)^{\sigma-1}$ then increases:

$$
\begin{aligned}
-\frac{\partial \varphi_{d}^{*}}{\partial \tau} \frac{\tau}{\varphi_{d}^{*}} & =\left[1+\frac{\left(f+f_{d}\right) J^{\prime}\left(\varphi_{d}^{*}\right) \varphi_{d}^{*}}{f J^{\prime}\left(\varphi_{s}^{*}\right) \varphi_{s}^{*}+f_{x} J^{\prime}\left(\varphi_{x}^{*}\right) \varphi_{x}^{*}}\right]^{-1} \\
& =[1+\tau^{\sigma-1} \underbrace{\int_{\varphi_{s}^{*}}^{\varphi_{d}^{*}} x^{\sigma-1} g(x) d x}_{=0, \text { since } \varphi_{d}^{*} \notin\left[\varphi_{s}^{*}, \varphi_{d}^{*}\right)}+\int_{\varphi_{x}^{*}}^{\infty} x^{\sigma-1} g(x) d x
\end{aligned}
$$

\footnotetext{
${ }^{11}$ Recall that $r_{c}^{x}(\varphi)=\tau^{1-\sigma} r_{c}^{d}(\varphi), \forall \varphi \geq \varphi_{d}^{*}$
} 


$$
\begin{aligned}
& =\left[1+\tau^{\sigma-1} \frac{\int_{\varphi_{d}^{*}}^{\infty} x^{\sigma-1} g(x) d x}{\int_{\varphi_{x}^{*}}^{\infty} x^{\sigma-1} g(x) d x}\right]^{-1} \\
& <\left[1+\tau^{\sigma-1}\right]
\end{aligned}
$$

since $\int_{\varphi_{d}^{*}}^{\infty} x^{\sigma-1} g(x) d x / \int_{\varphi_{x}^{*}}^{\infty} x^{\sigma-1} g(x) d x>1$ as $\varphi_{d}^{*}<\varphi_{x}^{*}$. Hence,

$$
\begin{aligned}
\frac{\partial\left[\frac{1+\tau^{1-\sigma}}{\left(\varphi_{d}^{*}\right)^{\sigma-1}}\right]}{\partial \tau} & =\frac{1+\tau^{1-\sigma}}{\left(\varphi_{d}^{*}\right)^{\sigma-1} \tau}\left[\frac{(1-\sigma) \tau^{1-\sigma}}{1+\tau^{1-\sigma}}-(\sigma-1) \frac{\partial \varphi_{d}^{*}}{\partial \tau} \frac{\tau}{\varphi_{d}^{*}}\right] \\
& =\frac{1+\tau^{1-\sigma}}{\left(\varphi_{d}^{*}\right)^{\sigma-1} \tau}(\sigma-1)\left[-\frac{\partial \varphi_{d}^{*}}{\partial \tau} \frac{\tau}{\varphi_{d}^{*}}-\left(1+\tau^{\sigma-1}\right)^{-1}\right] \\
& <0
\end{aligned}
$$

That is, the combined sales of regular exporters rise when $\tau$ decrease.

The profit change of a pure exporter $\left(\varphi_{s}^{*} \leq \varphi<\varphi_{d}^{*}\right)$ that is already in processing trade prior to falling $\tau$ can be written as:

$$
\begin{aligned}
\Delta \pi_{c}^{s}(\varphi) & =\pi_{c}^{s \prime}(\varphi)-\pi_{c}^{s}(\varphi) \\
& =\frac{1}{\sigma}\left[r_{c}^{s \prime}(\varphi)-r_{c}^{s}(\varphi)\right] \\
& =\varphi^{\sigma-1} f w_{c}\left[\frac{1}{\left(\varphi_{s}^{* \prime}\right)^{\sigma-1}}-\frac{1}{\left(\varphi_{s}^{*}\right)^{\sigma-1}}\right],
\end{aligned}
$$

the term in the bracket is positive since $\varphi_{s}^{* \prime}<\varphi_{s}^{*}$. The pure exporter that export both before and after the change in $\tau$ enjoy a profit increases.

The drop in $\tau$ forces previous less efficient domestic producers with productivity level $\left(\varphi_{d}^{*} \leq \varphi<\varphi_{d}^{* \prime}\right)$ in China pursuing processing trade, the profit change of this type of firms can be written as:

$$
\begin{aligned}
\Delta \pi(\varphi) & =\pi_{c}^{s}(\varphi)-\pi_{c}^{d}(\varphi) \\
& =\frac{1}{\sigma}\left[r_{c}^{s}(\varphi)-r_{c}^{d}(\varphi)\right]-f_{d} w_{c} \\
& =w_{c} \varphi^{\sigma-1}\left(\frac{f}{\varphi_{s}^{* \sigma-1}}-\frac{f+f_{d}}{\varphi_{d}^{* \sigma-1}}\right)-f_{d} w_{c},
\end{aligned}
$$

substituting (7) and (8) into the above equation reveals the term in the bracket must be negative. The switching from regular production mode to processing trade incurs both revenue and profit loss.

As was the case with the decrease in $f_{x}$, falling variable trade costs $\tau$ shift down the export productivity level from $\varphi_{x}^{*}$ to $\varphi_{x}^{* \prime}$. This generates the entry of new firms into the export market. All the new regular exporters enjoy a revenue gain, but only a portion of these firms also increase their profits. Specifically, this profit change is negative for the new exporting firms with the cutoff productivity level $\varphi_{x}^{* \prime}$

$$
\Delta \pi\left(\varphi_{x}^{* \prime}\right)=\frac{r_{c}^{d^{\prime}}\left(\varphi_{x}^{* \prime}\right)}{\sigma}+\frac{r_{c}^{x}\left(\varphi_{x}^{* \prime}\right)}{\sigma}-\left(f+f_{d}+f_{x}\right) w_{c}-\left[\frac{r_{c}^{d}\left(\varphi_{x}^{* \prime}\right)}{\sigma}-\left(f+f_{d}\right) w_{c}\right]
$$




$$
\begin{aligned}
& =\frac{r_{c}^{d^{\prime}}\left(\varphi_{x}^{* \prime}\right)}{\sigma}+\underbrace{\frac{r_{c}^{x \prime}\left(\varphi_{x}^{* \prime}\right)}{\sigma}-f_{x} w_{c}}_{=\pi_{c}^{x}\left(\varphi_{x}^{* \prime}\right)=0}-\frac{r_{c}^{d}\left(\varphi_{x}^{* \prime}\right)}{\sigma} \\
& =\frac{1}{\sigma}\left(r_{c}^{d^{\prime}}\left(\varphi_{x}^{* \prime}\right)-r_{c}^{d}\left(\varphi_{x}^{* \prime}\right)\right)<0 .
\end{aligned}
$$

Therefore, the firms with productivity $\varphi>\varphi^{\dagger}$ where $\varphi_{x}^{* \prime}<\varphi^{\dagger}<\varphi_{x}^{*}$ increase their profits. Firms with productivity level $\varphi>\varphi_{x}^{*}$ that export both before and after the change in $\tau$ enjoy a profit increase that is proportional to their combined revenue increase (their fixed costs do not change) and is increasing in their productivity $\varphi$ :

$$
\begin{aligned}
\Delta \pi(\varphi) & =\frac{1}{\sigma}\left[r^{\prime}(\varphi)-r(\varphi)\right] \\
& =\varphi^{\sigma-1} f w_{c}\left[\frac{1+\left(\tau^{\prime}\right)^{\sigma-1}}{\left(\varphi_{d}^{* \prime}\right)^{\sigma-1}}-\frac{1+\tau^{\sigma-1}}{\left(\varphi_{d}^{*}\right)^{\sigma-1}}\right],
\end{aligned}
$$

where the term in the bracket must be positive.

\section{C.3 Decrease in Domestic Trade Costs}

Changes in the cutoff levels:

Differentiating $f_{d}$ with respect to $\varphi_{x}^{*}=\tau \varphi_{d}^{*}\left(\frac{f_{x}}{f+f_{d}}\right)^{\frac{1}{\sigma-1}}$ yields $\frac{\partial \varphi_{x}^{*}}{\partial f_{d}}=\frac{1}{1-\sigma} \frac{\varphi_{x}^{*}}{f+f_{d}}+\frac{\varphi_{x}^{*}}{\varphi_{d}^{*}} \frac{\partial \varphi_{d}^{*}}{\partial f_{d}}$.

Differentiating $f_{d}$ with respect to $\varphi_{s}^{*}=\tau \varphi_{d}^{*}\left(\frac{f}{f+f_{d}}\right)^{\frac{1}{\sigma-1}}$ yields $\frac{\partial \varphi_{s}^{*}}{\partial f_{d}}=\frac{1}{1-\sigma} \frac{\varphi_{s}^{*}}{f+f_{d}}+\frac{\varphi_{s}^{*}}{\varphi_{d}^{*}} \frac{\partial \varphi_{d}^{*}}{\partial f_{d}}$.

Differentiating $f_{d}$ with respect to $\varphi_{x f}^{*}=\tau \varphi_{d f}^{*}\left(\frac{f_{x}}{f+f_{d}}\right)^{\frac{1}{\sigma-1}}$ yields $\frac{\partial \varphi_{x f}^{*}}{\partial f_{d}}=\frac{1}{1-\sigma} \frac{\varphi_{x f}^{*}}{f+f_{d}}+\frac{\varphi_{x f}^{*}}{\varphi_{d f}^{*}} \frac{\partial \varphi_{d f}^{*}}{\partial f_{d}}$.

Differentiating (21) and 22 in both countries with respect to $f_{d}$ and using the above three conditions

$$
\begin{aligned}
\frac{\partial \varphi_{d}^{*}}{\partial f_{d}} & =\frac{\frac{1}{\sigma-1} \frac{f}{f+f_{d}} J^{\prime}\left(\varphi_{s}^{*}\right) \varphi_{s}^{*}+\frac{1}{\sigma-1} \frac{f_{x}}{f+f_{d}} J^{\prime}\left(\varphi_{x}^{*}\right) \varphi_{x}^{*}-J\left(\varphi_{d}^{*}\right)}{f J^{\prime}\left(\varphi_{s}^{*}\right) \frac{\varphi_{s}^{*}}{\varphi_{d}^{*}}+\left(f+f_{d}\right) J^{\prime}\left(\varphi_{d}^{*}\right)+f_{x} J^{\prime}\left(\varphi_{x}^{*}\right) \frac{\varphi_{x}^{*}}{\varphi_{d}^{*}}}>0, \\
\frac{\partial \varphi_{d f}^{*}}{\partial f_{d}} & =\frac{\frac{1}{\sigma-1} \frac{f_{x}}{f+f_{d}} J^{\prime}\left(\varphi_{x f}^{*}\right) \varphi_{x f}^{*}-J\left(\varphi_{d f}^{*}\right)}{\left(f+f_{d}\right) J^{\prime}\left(\varphi_{d f}^{*}\right)+f_{x} J^{\prime}\left(\varphi_{x f}^{*}\right) \frac{\varphi_{x f}^{*}}{\varphi_{d f}^{*}}}>0 .
\end{aligned}
$$

Since in China $J^{\prime}\left(\varphi_{d}^{*}\right)<0 \forall \varphi$, and $\left(f+f_{d}\right) J^{\prime}\left(\varphi_{d}^{*}\right) \frac{\partial \varphi_{d}^{*}}{\partial f_{d}}+J\left(\varphi_{d}^{*}\right)<0$

$$
\begin{aligned}
& \frac{\partial \varphi_{x}^{*}}{\partial f_{d}}=-\frac{\left(f+f_{d}\right) J^{\prime}\left(\varphi_{d}^{*}\right) \frac{\partial \varphi_{d}^{*}}{\partial f_{d}}+J\left(\varphi_{d}^{*}\right)}{f J^{\prime}\left(\varphi_{s}^{*}\right) \frac{\varphi_{*}^{*}}{\varphi_{x}^{*}}+f_{x} J^{\prime}\left(\varphi_{x}^{*}\right)}<0, \\
& \frac{\partial \varphi_{s}^{*}}{\partial f_{d}}=-\frac{\left(f+f_{d}\right) J^{\prime}\left(\varphi_{d}^{*}\right) \frac{\partial \varphi_{d}^{*}}{\partial f_{d}}+J\left(\varphi_{d}^{*}\right)}{f J^{\prime}\left(\varphi_{s}^{*}\right)+f_{x} J^{\prime}\left(\varphi_{x}^{*}\right) \frac{\varphi_{x}^{*}}{\varphi_{s}^{*}}}<0 .
\end{aligned}
$$

And in Foreign Country $J^{\prime}\left(\varphi_{d f}^{*}\right)<0 \forall \varphi$, and $\left(f+f_{d}\right) J^{\prime}\left(\varphi_{d f}^{*}\right) \frac{\partial \varphi_{d f}^{*}}{\partial f_{d}}+J\left(\varphi_{d f}^{*}\right)<0$

$$
\frac{\partial \varphi_{x f}^{*}}{\partial f_{d}}=-\frac{J\left(\varphi_{d f}^{*}\right)+\left(f+f_{d}\right) J^{\prime}\left(\varphi_{d f}^{*}\right) \frac{\partial \varphi_{d f}^{*}}{\partial f_{d}}}{f_{x} J^{\prime}\left(\varphi_{x f}^{*}\right)}<0 .
$$




\section{C.3.1 Welfare}

Recall the welfare per worker in China is $\mathbb{W}_{c}=\frac{w_{c}}{R_{c}}=\rho\left(\frac{L}{\sigma w_{c}\left(f+f_{d}\right)}\right)^{\frac{1}{\sigma-1}} \varphi_{d}^{*}$. The direction of the welfare change induced by a drop in the domestic trade costs is not immediately obvious as $f_{d}$ enters into the welfare equation. (Recall that a decrease in $f_{d}$ induces a decline in $\varphi_{d}^{*}$ as $\frac{\partial \varphi_{d}^{*}}{\partial f_{d}}>0$ ). The direction of the welfare change therefore depends on the direction of the change in $\frac{\left(\varphi_{d}^{*}\right)^{\sigma-1}}{f+f_{d}}$.

\section{Proof that $\frac{\left(\varphi_{d}^{*}\right)^{\sigma-1}}{f+f_{d}}$ Increases when $f_{d}$ decreases}

The differential change in $\frac{\left(\varphi_{d}^{*}\right)^{\sigma-1}}{f+f_{d}}$ is given by:

$$
\frac{\partial\left(\frac{\varphi_{d}^{* \sigma-1}}{f+f_{d}}\right)}{\partial f_{d}}=\frac{\varphi_{d}^{* \sigma-1}}{\left(f+f_{d}\right)^{2}}\left[(\sigma-1) \frac{\partial \varphi_{d}^{*}}{\partial f_{d}} \frac{f+f_{d}}{\varphi_{d}^{*}}-1\right]<0 .
$$

Hence, a decrease in $f_{d}$ generates a welfare gain.

Recall that the aggregate revenue of domestic firms is exogenously given by $R_{c}=w_{c} L$ and $R_{f}=$ $w_{f} L$. Hence, $r_{c}^{s}(\varphi) / R_{f}$ represents a Chinese pure exporter's market share in Foreign Country. In addition, we have $r_{c}^{s}(\varphi)=\left(\varphi / \varphi_{s}^{*}\right)^{\sigma-1} \sigma w_{c} f\left(\forall \varphi_{s}^{*} \leq \varphi<\varphi_{d}^{*}\right) . r_{c}^{s}(\varphi)$ therefore decreases with falling domestic trade barriers $f_{d}$ since this change induces a rise in the cutoff productivity level of pure exporters $\left(\varphi_{s}^{*} \uparrow\right)$. Thus $r_{c}^{s \prime}(\varphi)<r_{c}^{s}(\varphi) \forall \varphi_{s}^{*} \leq \varphi<\varphi_{d}^{*}$ whenever $f_{d}^{\prime}<f_{d}$ (since $\varphi_{s}^{* \prime}>\varphi_{s}^{*}$ ).

Falling $f_{d}$ creates the entry of new regular producers in both countries. Take China as an example, a decline in $f_{d}$ leads to efficient pure exporters switching from processing trade to regular production and starting to serve the domestic market. For a new domestic firm $\left(\varphi_{d}^{* \prime}<\varphi \leq \varphi_{d}^{*}\right)$, the profit change can be written:

$$
\begin{aligned}
\Delta \pi(\varphi) & =\pi_{c}^{d}(\varphi)-\pi_{c}^{s}(\varphi) \\
& =\frac{1}{\sigma}\left[r_{c}^{d}(\varphi)-r_{c}^{s}(\varphi)\right]-f_{d} w_{c} \\
& =w_{c} \varphi^{\sigma-1}\left(\frac{f+f_{d}}{\varphi_{d}^{* \sigma-1}}-\frac{f}{\varphi_{s}^{* \sigma-1}}\right)-f_{d} w_{c}
\end{aligned}
$$

substituting (7) and (8) into the above equation reveals the term in the bracket must be positive. The profit change $\Delta \pi(\varphi)$ is thus an increasing function of firm's productivity $\varphi$. Therefore, the new domestic firms increase their revenue and profits. The impact of changing production mode is similar to Melitz (2003) of moving from autarky to trade.

For Chinese firms $\left(\varphi_{d}^{*} \leq \varphi<\varphi_{x}^{*}\right)$ that already in domestic market prior to the change in $f_{d}$, the impact of falling $f_{d}$ on the profit is

$$
\begin{aligned}
\Delta \pi(\varphi) & =\pi_{c}^{d^{\prime}}(\varphi)-\pi_{c}^{d}(\varphi) \\
& =\frac{1}{\sigma}\left[r_{c}^{d^{\prime}}(\varphi)-r_{c}^{d}(\varphi)\right]-\left(f+f_{d}{ }^{\prime}\right) w_{c}-\left(f+f_{d}\right) w_{c}
\end{aligned}
$$




$$
=w_{c} \varphi^{\sigma-1}\left[\frac{f+f_{d}{ }^{\prime}}{\left(\varphi_{d}^{* \prime}\right)^{\sigma-1}}-\frac{f+f_{d}}{\varphi_{d}^{* \sigma-1}}\right]-\left(f_{d}^{\prime}-f_{d}\right) w_{c}
$$

C.5 reveals $\frac{\partial\left(\frac{f+f_{d}}{\varphi_{d}^{* \sigma-1}}\right)}{\partial f_{d}}>0$. This implies that $\frac{f+f_{d}}{\varphi_{d}^{* \sigma-1}}$ decreases when $f_{d}$ falling down and hence that $\frac{f+f_{d}^{\prime}}{\left(\varphi_{d}^{* \prime}\right)^{\sigma-1}}<\frac{f+f_{d}}{\varphi_{d}^{* \sigma-1}}$. This inequality implies that the $\Delta \pi(\varphi)$ is a decreasing function of $\varphi$ since the bracket in C.2 is negative. Therefore, an existing domestic producer experiences both revenue and profits loss in the new equilibrium.

The change in profits earned by a firm that export in the new equilibrium $\left(\varphi \geq \varphi_{x}^{* \prime}\right)$ can be written:

$$
\Delta \pi(\varphi)=\left(1+\tau^{1-\sigma}\right) \varphi^{\sigma-1} w_{c}\left[\frac{f+f_{d}^{\prime}}{\left(\varphi_{d}^{* \prime}\right)^{\sigma-1}}-\frac{f+f_{d}}{\varphi_{d}^{* \sigma-1}}\right]-\left(f_{d}{ }^{\prime}-f_{d}\right) w_{c} .
$$

The direction of the change in combined domestic and export sales also depends on $\frac{f+f_{d}}{\varphi_{d}^{* \sigma-1}}$. It showed above that these combined profit will decrease when $f_{d}$ decreases. 